\title{
The role of external triggers in flow shear arcs in the dayside aurora
}

\author{
P. E. Sandholt ${ }^{1}$ and C. J. Farrugia ${ }^{2}$ \\ ${ }^{1}$ Department of Physics, University of Oslo, Oslo, Norway \\ ${ }^{2}$ Space Science Center, University of New Hampshire, Durham
}

Received: 14 March 2008 - Accepted: 30 June 2008 - Published: 4 August 2008

\begin{abstract}
In case studies we relate dayside auroral transients to IMF $B_{y}$-distorted plasma convection cells based on high-resolution observations from the ground. We selected three days representing positive and negative IMF $B_{y}$ conditions when SuperDARN returned reliable dayside convection patterns in the sector of our optical observations from Ny Ålesund, Svalbard (76 MLAT). We combine two perspectives on the dayside aurora, the local and the global. In the first we derive the fine-structure of dayside precipitation/convection as a function of magnetic latitude (MLAT) and magnetic local time (MLT), which is necessary to understand the local M-I coupling processes (Birkeland current structure). The larger perspective (quasi-global dayside aurora) may be used to shed light on the solar windmagnetosphere interconnection topology. The auroral morphology consists of brightening events and poleward moving auroral forms (PMAFs) in the pre- and postnoon sectors longitudinally separated by a band of strongly attenuated aurora near noon. We find that the MLT-dependent spatial structure in the dayside aurora (PMAFs/prenoon - "midday gap aurora" - PMAFs/postnoon) which is present during stable IMF conditions is altered by temporal structure during intervals of IMF/solar wind plasma transients. The focus is on the PMAF substructure (so-called "rebrightening forms") which we identify as dynamical plasma flow shear arcs (FSAs) in $B_{y}$-distorted dawn- and dusk-centered convection cells in the close vicinity of the cusp.
\end{abstract}

Keywords. Magnetospheric physics (Auroral phenomena; Magnetopause, cusp, and boundary layers; Storms and substorms)

Correspondence to: P. E. Sandholt

(p.e.sandholt@fys.uio.no)

\section{Introduction}

Poleward moving auroral forms (PMAFs) have been recognized for many years as a major ionospheric signature of impulsive reconnection at the magnetopause. They have been related to other ionospheric and cusp signatures of reconnection. It follows that their dynamics reflects changes in the reconnective coupling including the effects of other solar wind/IMF transients. They are sensitive monitors and the dynamics (brightenings, expansion etc.) can be related to underlying convection flows. They can thus furnish important clues on the reconnection process itself, and indeed they have been the object of recent hybrid (kinetic ions, fluid electrons) simulations (Omidi and Sibeck, 2007).

In this paper we shall report three case studies of highresolution observations of the dayside aurora and plasma convection obtained by ground instrumentation. We emphasize PMAFs and we shall study both the local and the more global aspects of the dayside aurora. In the local perspective we study the role of local flow shear in exciting substructure of PMAFs. The local auroral structure and flow shear are placed in the context of the large-scale dayside plasma convection pattern consisting of dawn-centered and dusk-centered convection cells and the corresponding auroral forms/activities. The quasi-global perspective on the dayside aurora and plasma convection, obtained by combining the observations in the prenoon, midday, and postnoon sectors, is discussed in relation to the IMF-magnetosphere interconnection topology. The study is restricted to intervals when a significant IMF $B_{y}$ component is present, giving rise to $B_{y}$ distorted (asymmetric) convection cells. In recent studies we have documented aurora-convection configurations persisting during steady southeast/west IMF and solar wind conditions (Sandholt and Farrugia, 2007a,b). Here we shall focus on the responses of aurora/convection to specific transients in the IMF orientation and the solar wind dynamic pressure. Thus we address the question of dayside auroral transients

Published by Copernicus Publications on behalf of the European Geosciences Union. 
directly driven by fluctuations in external parameters such as the solar wind dynamic pressure and the $B_{y}$ and $B_{z}$ components of the IMF (see also Newell and Sibeck, 1993). Our case studies of dayside auroral activity from the ground perspective is complementary to the average picture of dayside electron acceleration events in relation to convection which has been established by Newell et al. (2005).

PMAFs were originally described by Vorobjev et al. (1975) who reported the poleward propagation of forms on the dayside during intervals of disturbed magnetic conditions (substorms) when the dayside oval expanded equatorward. A revival of interest in PMAFs occurred in the mid-1980s associated with the search for ionospheric signatures of magnetopause flux transfer events (FTEs) and the associated newly reconnected field lines. FTEs had been identified by magnetic field perturbations at the magnetopause, specifically a bipolar variation in the field component normal to the magnetopause and simultaneous deflections in the tangential components. They have been interpreted in terms of transient magnetopause reconnection (Russell and Elphic, 1978).

As part of an investigation of the role played by transient reconnection in the dynamics of the magnetosphereionosphere system a search for ionospheric FTE signatures in the dayside aurora, plasma convection, and magnetic deflections was initiated (Goertz et al., 1985; Sandholt et al., 1986; McHenry and Clauer, 1987). Signatures of FTE flux tubes in the local dayside aurora, as observed from one single station, and the associated local magnetic deflections and plasma convection features were soon identified (Sandholt et al., 1990). The local auroral signature consisted of the following essential elements: (i) short-lived (1-2 min) brightening ("breakup") events (dayside LLBL/BPS-type precipitation) followed by (ii) $\sim 10-15$ min long PMAFs extending into the regime of mantle precipitation (high-latitude polar cusp) (Sandholt et al., 1993), (iii) a substructure of PMAFs consisted of arcs appearing in the region of the flow reversal of the Southwood-type FTE-related convection pattern (Southwood, 1987; Sandholt et al., 1990), and (iv) an event recurrence every 5-10 min. Later, statistical studies showed the presence of a clear minimum in the PMAF activity in the midday sector (Fasel, 1995; Karlson et al., 1996). Closer studies of the IMF dependence showed that the classical PMAFs were observed exclusively in intervals when, in addition to the negative $B_{z}$ component, a significant IMF $B_{y}$ component ( $\geq 2 \mathrm{nT}$ ) was also present (Sandholt et al., 2004). This IMF state is accompanied by a distorted 2-cell convection pattern with a characteristic $B_{y}$-related dawn-dusk asymmetry (Weimer, 1995).

Recent studies of the quasi-global dayside aurora under steady southeast IMF conditions showed that PMAFs originating in the postnoon sector (13:00-15:00 MLT) are separated from the PMAFs originating in the prenoon sector (09:00-11:00 MLT) by a less intense auroral band around noon which is often referred to as the "midday gap aurora" (Cogger et al., 1977; Sandholt and Farrugia, 2003).
The latter emission band also often appears in the form of a midday auroral brightening sequence (MABS). MABS are localized in the close vicinity of the zero-point potential line separating the dawn-centered and dusk-centered convection cells (Sandholt and Farrugia, 2007a). Thus, in contrast to to the PMAFs/prenoon and PMAFs/postnoon the the midday gap and the associated MABS occur in a region of low flow shear (vorticity) where less intense Birkeland currents are expected/observed (Iijima and Potemra, 1978).

The association of PMAFs/prenoon and PMAFs/postnoon with the distorted dawn-centered and dusk-centered convection cells, respectively, led to an investigation of an IMF $B_{y}$-related dawn-dusk asymmetry in the PMAF latitudinal structure (Sandholt and Farrugia, 2007b). This PMAF asymmetry is closely related to the different Birkeland current configurations existing in the two MLT sectors. Assuming that the three auroral phenomena (PMAFs/prenoon, MABS, PMAFs/postnoon) are ionospheric signatures of magnetopause FTEs the implication is that the geoeffectiveness (as measured by the aurora - Birkeland current intensity) of FTEs is different in the different local time sectors (Sandholt and Farrugia, 2007b).

The auroral configuration described above for steady southeast/west IMF conditions maybe described in terms of an S-shaped IMF - magnetosphere interconnection topology (reconnection line) as described by Moore et al. (2002). The tilted X-line running through the subsolar region extends to high latitudes in opposite hemispheres on the dawn and dusk sides. In this study we shall study the response of the dayside aurora and plasma convection to northward rotations of the IMF from the southeast/west states. In selected cases we shall establish the quasi-global perspective of the dayside aurora (09:00-14:00 MLT sector) and demonstrate the 2-dimensional evolution of the auroral events by using ASC observations. These observations may shed new light on the question of spatial and temporal evolution of the reconnection events on the magnetopause associated with IMF transients. This is one aspect of our study. The other aspect is the substructure of PMAFs themselves, which appears from the local perspective on the dayside aurora.

In the early 1990s Fasel performed a systematic study of the details of the PMAF activity and made a classification of the different types based on difference in the complexity of their brightening history (Fasel et al., 1994a; Fasel, 1995). The PMAFs substructure was referred to by Fasel as "multiple brightenings" or "rebrightening" forms. In the simplest case the initial brightening is followed by a PMAF with decreasing intensity during the later phase of poleward expansion (type 1 events). In other cases the initial activation is followed by one or more "rebrightenings" appearing at successively higher latitudes (type 2). The type 3 events are similar to type 2, but slow down and stop after having moved into the polar cap. Thus, in the third category the northernmost stage appears as a long-lasting (10-15 $\mathrm{min})$ form with or without rebrightenings. The phenomenon of "rebrightening" forms 
appearing at successively higher latitude was explained in terms of patchy reconnection in a multiple $\mathrm{X}$-line configurations (Fasel et al., 1994b; Omidi and Sibeck, 2007).

In this study we shall discuss the substructure of PMAFs in relation to plasma convection data obtained by the SuperDARN network of ground-based radars. Emphasis is placed on the role played by local ionospheric flow shears. It is well known that dayside aurorae and polar cap (sun-aligned) arcs may appear in regions of upward-directed Birkeland currents required by current continuity in regions of local flow shear (Reiff et al., 1978; Carlson et al., 1988; Sandholt et al., 1990; Frey et al., 2003; Oksavik et al., 2004, 2005). Here we shall investigate the role played by such flow shears in the excitation of the PMAF substructure we refer to as equatorward boundary intensifications (EBIs) and poleward boundary intensifications (PBIs). The most intense auroral events we study are found to be transient flow shear arcs (FSAs) triggered by interplanetary magnetic field transients and/or associated pulses of enhanced solar wind dynamic pressure. That auroral forms may be directly driven by such external triggers has been anticipated by Newell and Sibeck (1993). Thus, this paper addresses the role of external triggers in the excitation of flow shear arcs in the cusp region including the multiple brightening of PMAFs.

\section{Observations on 3 December 1997}

\subsection{Case overview}

Figure 1 shows a schematic illustration of the auroraconvection relationship as derived from the observations obtained during the interval 05:40-09:30 UT, 3 December 1997. This is meant to be an extract of essential features of the observations representing three local time sectors (prenoon-noon-postnoon) on this day. This is what we refer to as the quasi-global perspective on the dayside aurora. Thus, this overview of the aurora-convection state contains both spatial (MLT/MLAT) and temporal structure. By the latter we mean features triggered by variations in the IMF and the solar wind dynamic pressure. By this case we shall also illustrate the three subcategories of PMAF brightening history described by Fasel (1995).

In this plot the observation site is marked by a solid dot, the scanning direction and the range of the MSP is shown as a double-arrowed line, and the all-sky camera (ASC) field of view is indicated by the circles. We stress the following elements: (i) PMAFs/prenoon in the dawn-centered convection cell with two phases of expansion: first noonward and then poleward in the fading phase (see thick arrows), (ii) the "midday gap aurora" with the characteristic midday auroral brightening sequence (MABS; marked by the three dots), (iii) PMAFs/postnoon with, and without, multiple brightenings during poleward expansions in the dusk-centered convection cell(s), and (iv) PMAFs/postnoon with intense, high-

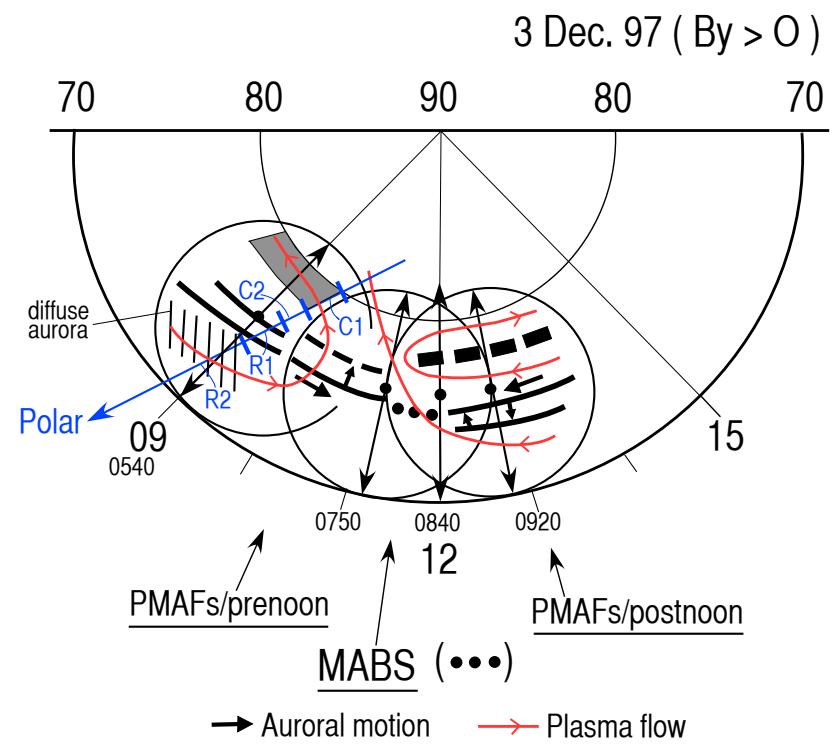

Fig. 1. Schematic illustration of aurora and plasma convection in MLT/MLAT coordinates representing the interval 05:40-09:30 UT on 3 December 1997. Approximate fields of view (at $630.0 \mathrm{~nm}$ ) of the MSP at Ny Ålesund are indicated by double-arrowed meridional lines for the times 05:40 UT, 07:50 UT, 08:40 UT, and 09:20 UT. Magnetic north is up. Circles mark the FOVs of the ASC $(630.0 \mathrm{~nm})$ at the same selected times. Auroral motions are indicated by arrows attached to the respective forms. Plasma convection streamlines are marked red.

latitude brightening events (PBIs; type 3 events) associated with plasma flow transients directly driven by the IMF/solar wind. The latter PBIs are triggered by IMF northward turnings and are associated with the westward protrusion of a specific dusk-centered convection cell. We shall argue that this is a lobe cell (in the Discussion). The PBIs (marked by thick dashed line) appear in a region of clockwise flow vorticity. Thus the bright auroral form located well north of Ny Ålesund is accompanied by a strong flow shear which is consistent with an intense upward-directed Birkeland current. This leads us to refer to this auroral form as a flow shear arc (FSA; see Discussion).

Two different temporal structures are included in Fig. 1. One is the above mentioned westward protrusion of the duskside convection cell with the associated flow shear arc (FSA). This is the response to an IMF transient in which the IMF rotated due east (the 09:20 UT event). The other is the response to a southward turning giving rise to equatorward expansion of the aurora from 08:40 UT onwards (marked by arrow pointing down in the postnoon sector). This type of equatorward motion of the cusp equatorward boundary is often called an "erosion" event.

In this study we combine the different elements included in the previous studies (Maynard et al., 2001; Farrugia et al., 2003) and add a critical new element: the convection data from SuperDARN. We thereby obtain an interesting 


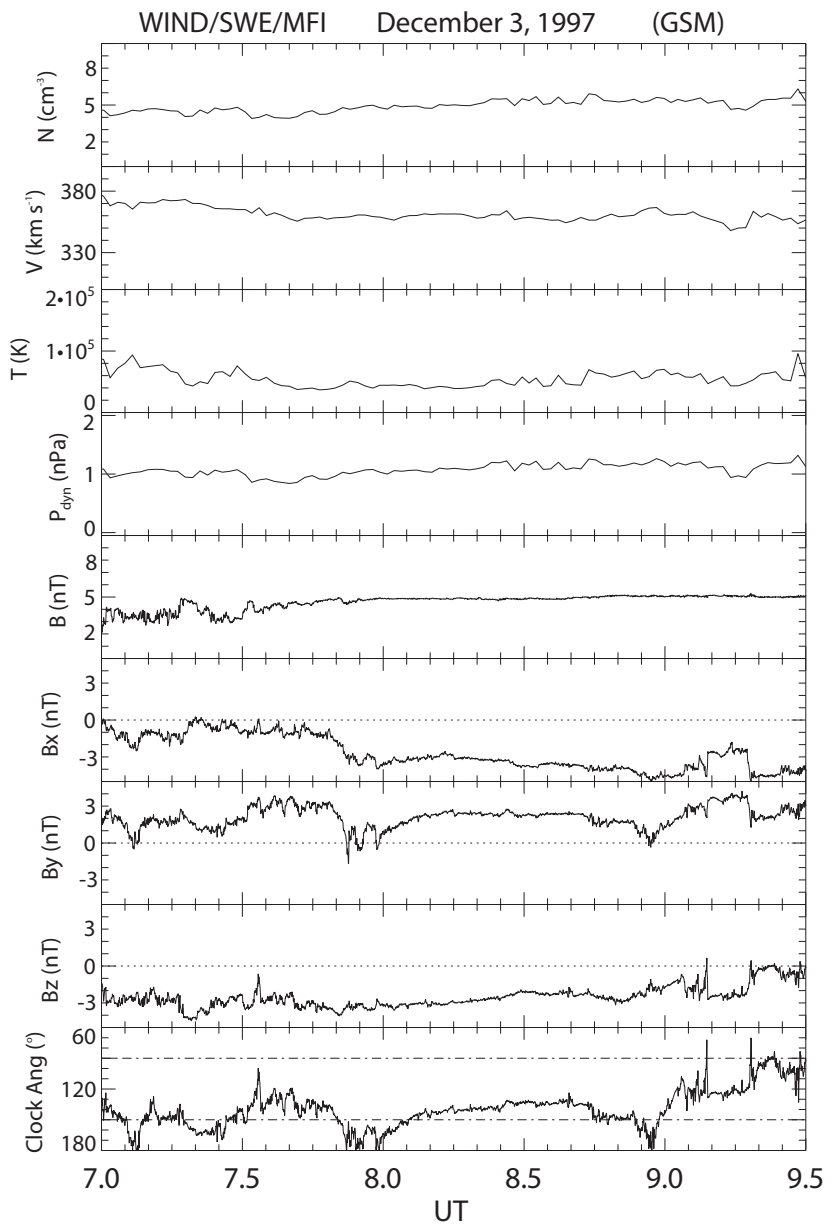

Fig. 2. Wind magnetic field and solar wind plasma data for the interval 07:00-09:30 UT. Panels from top to bottom shows proton density, bulk speed, temperature, dynamic pressure, the total magnetic field and its components $B_{x}, B_{y}$, and $B_{z}$. The bottom panel shows the IMF clock angle in the GSM Y-Z plane.

synthesis of the auroral and convection data available on this day. The combined ground-satellite observations near the 09:00 MLT meridian in Fig. 1 is included here for completeness. On this day spacecraft Polar, at mid-altitudes in the magnetosphere, crossed a wide range of MLATs in this midmorning sector under similar IMF conditions (south-east) as the later observations. The different field-aligned current regimes traversed by the spacecraft have been marked in the figure, as C1-C2-R1-R2 currents. Each region is characterized by different auroral forms as documented by the ground observations during the interval 05:30-06:00 UT (Farrugia et al., 2003). At lower latitudes, the traditional R1 and $\mathrm{R} 2$ regimes are associated with discrete forms and a diffuse green line aurora, respectively, as marked in the figure. The northernmost regime $(\mathrm{C} 1)$ is characterized by an outwarddirected Birkeland current and intense auroral emissions at both 557.7 and $630.0 \mathrm{~nm}$. The HYDRA instrument on Po- lar observed a characteristic sequence of ion/electron bursts. These plasma bursts are interpreted as solar wind plasma injected into the mid-altitude cusp in association with flux transfer events. The C1-C2 cusp currents poleward of the R1-R2 system is identical to the IMF $B_{y}$-related HCC-LCC currents of Taguchi et al. (1993). The ionospheric Pedersen closure current of the $\mathrm{C} 1-\mathrm{C} 2$ currents give rise to a distinct convection channel at the polar cap boundary in the midmorning sector during the prevailing IMF $B_{y}$ positive conditions (marked by the shaded area in the figure). The presence of this convection channel has been documented in Sandholt and Farrugia (2007b).

\subsection{Wind interplanetary data}

Interplanetary field and plasma data from the SWE (Ogilvie et al., 1995) and MFI (Lepping et al., 1995) instruments on spacecraft Wind are shown in Fig. 2 for the time interval 07:00-09:30 UT. At the center of the interval of interest Wind was at $(199.7,1.6,26.5) R_{E}$ upstream of Earth. Using $V_{x}$ the convection delay to the subsolar magnetopause is estimated as $1 \mathrm{hr}$ and the time in Fig. 2 has been shifted by this amount. From top to bottom the panels show the proton density, bulk speed, temperature and dynamic pressure followed by the total field, the GSM components of the field, and the polar angle in the GSM (YZ) plane, i.e. the clock angle. Wind observed a slow solar wind of below-average density, dynamic pressure. The IMF is tilted antisunward and pointing south with a strong and generally positive $B_{y}$ component.

\subsection{Auroral observations}

Figure 3 shows MSP data from Ny Ålesund during the interval 07:30-09:30 UT, representing the local time sector $\sim$ 11:00-13:00 MLT. The auroral activity around 09:00 MLT on this same day (indicated schematically in Fig. 3) is documented in Farrugia et al. (2003). Here we shall investigate the following: (i) PMAFs/prenoon: the auroral brightening forms appearing in the late prenoon sector (07:30-07:50 UT; $\sim$ 11:00-11:20 MLT), (ii) MABS: the much weaker "midday auroral brightening sequence" observed during the interval 07:50-08:40 UT (11:20-12:10 MLT), (iii) PMAFs/postnoon: the intense brightening forms in the early postnoon sector (08:40-09:00 UT; 12:10-12:30 MLT), and (iv) Multiple brightening PMAFs with intense, higher-latitude form during the interval 09:00-09:30 UT.

The attenuated emission (midday gap aurora) observed in the 11:20-12:10 MLT sector is delimited by the two vertical guidelines. The PMAF/prenoon activity during 07:3507:45 UT is characterized by an intense brightening in the south (near zenith) followed by a clear poleward expansion phase (07:38-07:45 UT). The high-latitude part (30-60 NZ) of this event persists for about $10 \mathrm{~min}$. This is a good example of a type 3 PMAF of Fasel (1995). 


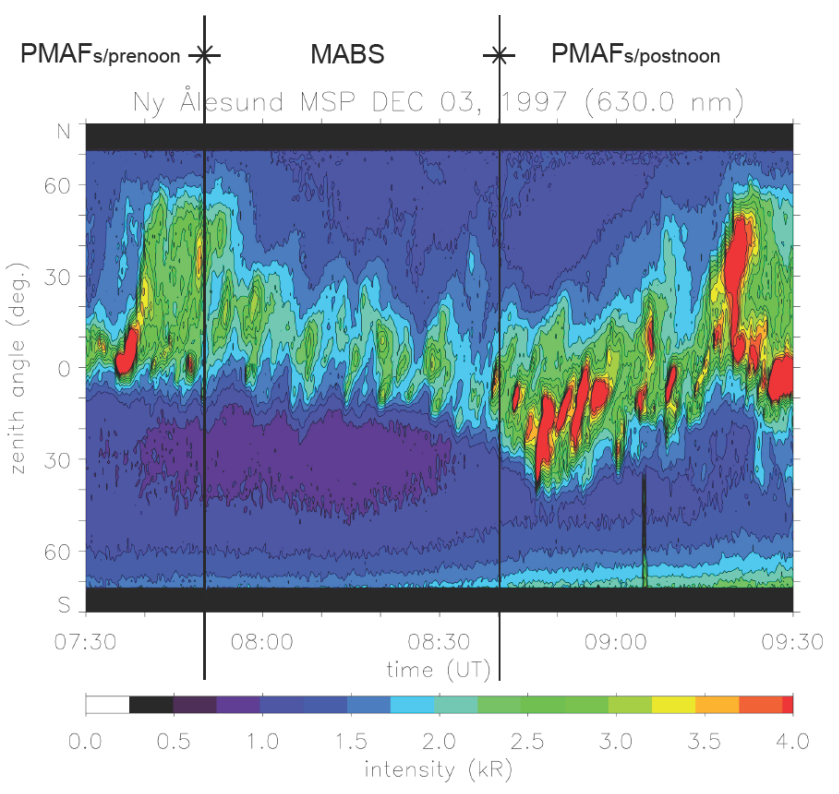

Fig. 3. Ny Ålesund meridian scanning photometer (MSP) data for the interval 07:30-09:30 UT (appr. 11:00-13:00 MLT). Line-ofsight emission intensity at $630.0 \mathrm{~nm}$ versus zenith angle and time is color coded according to the scale at the bottom. Magnetic north is up. Three auroral features (PMAFs/prenoon, MABS, and PMAFs/postnoon) are marked by vertical guidelines.

The PMAFs/postnoon (08:40-09:30 UT) may be divided in two subintervals according to the brightening structure. The earlier activity in the interval 08:40-09:00 UT may be identified as type 1 events while the activity in the interval 09:00-09:30 UT is more complex. The event at 09:1509:25 UT seems to be a type 3 event. It is characterized by a very intense "rebrightening form" in the north $\left(30-60^{\circ}\right.$ NZ). This is what we call a poleward boundary intensification (PBI). It is particularly intense in the $557.7 \mathrm{~nm}$ emission (not shown). The smaller event at 09:03-09:10 UT is similar, but the rebrightening is not so intense as that at 09:2009:25 UT. It may still be classified as a type 3 PMAF. The 2$\mathrm{D}$ characteristics of these auroral features will be illustrated by ASC images below. After the presentation of the ASC data we shall document the plasma convection characteristics associated with these phenomena, as observed by SuperDARN radars.

Figure 4 shows a schematic illustration of the IMF clock angle obtained by Wind (upper panel; see bottom panel of Fig. 2) and major features of the MSP data shown in Fig. 3 for the interval 07:00-09:30 UT. Auroral forms/activities corresponding to three MLT sectors (PMAFs/prenoon, MABS, and PMAFs/postnoon) are marked in the figure. We note that the Wind to ground propagation delay in this case may differ for the PMAFs/prenoon and PMAFs/postnoon activities (Maynard et al., 2001). The delay applied here $(1 \mathrm{~h})$ is that which is relevant for the PMAFs/postnoon activi-

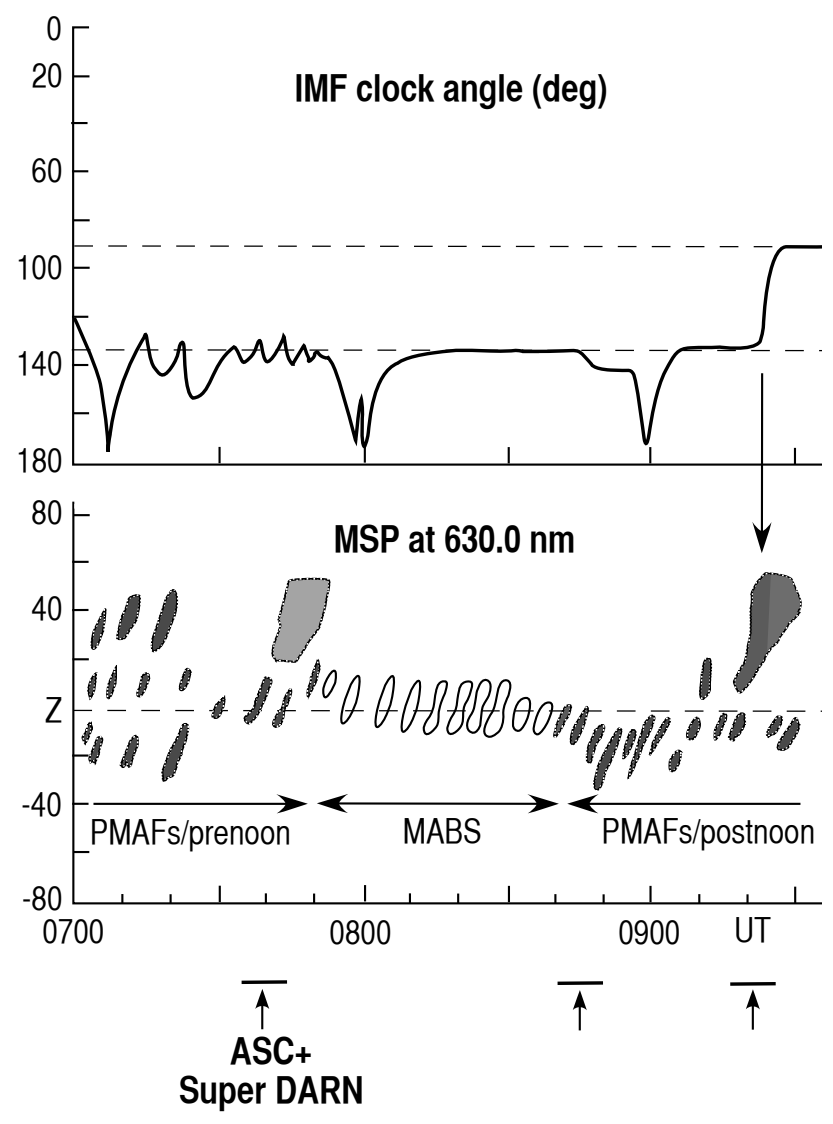

Fig. 4. Upper panel shows the IMF clock angle (Wind time plus $1 \mathrm{~h}$ ). Lower panel shows a schematic summary of the Ny Ålesund MSP data for the interval 0700-0930 UT representing three MLT sectors: prenoon, noon, and postnoon.

ties. It thus appears that the major type $3 \mathrm{PMAF} /$ postnoon at 09:20 UT is likely triggered by the rapid IMF transition involving a clock angle rotation from 135 to $90^{\circ}$ (see Fig. 2). Below we shall report ASC observations of the 2-D aspects of the aurora and SuperDARN spatial convection plots for the times indicated by horizontal bars at the bottom of the figure.

We shall next document the 2-D characteristics of the type 3 PMAF/prenoon event at 07:34-07:44 UT, the type 1 PMAF/postnoon event at 08:40-08:50 UT and the type 3 event at 09:15-09:25 UT. All these events are clearly manifested in the MSP plot in Fig. 3.

Figure 5 shows ASC images at $630.0 \mathrm{~nm}$ obtained at $\mathrm{Ny}$ Ålesund during the interval 07:34-07:44 UT. The perspective is looking down on the aurora. The central vertical line marks the $\sim 11: 00$ MLT meridian and gives the location of the station at this UT. We recognize the brightening of a form in the western (left) part of the FOV at 07:34-07:36 UT (upper row). This form expanded eastward (noonward) during the interval 07:34-07:38 UT. The major brightening in the MSP plot at 07:35 UT (Fig. 3) marks the time when the 

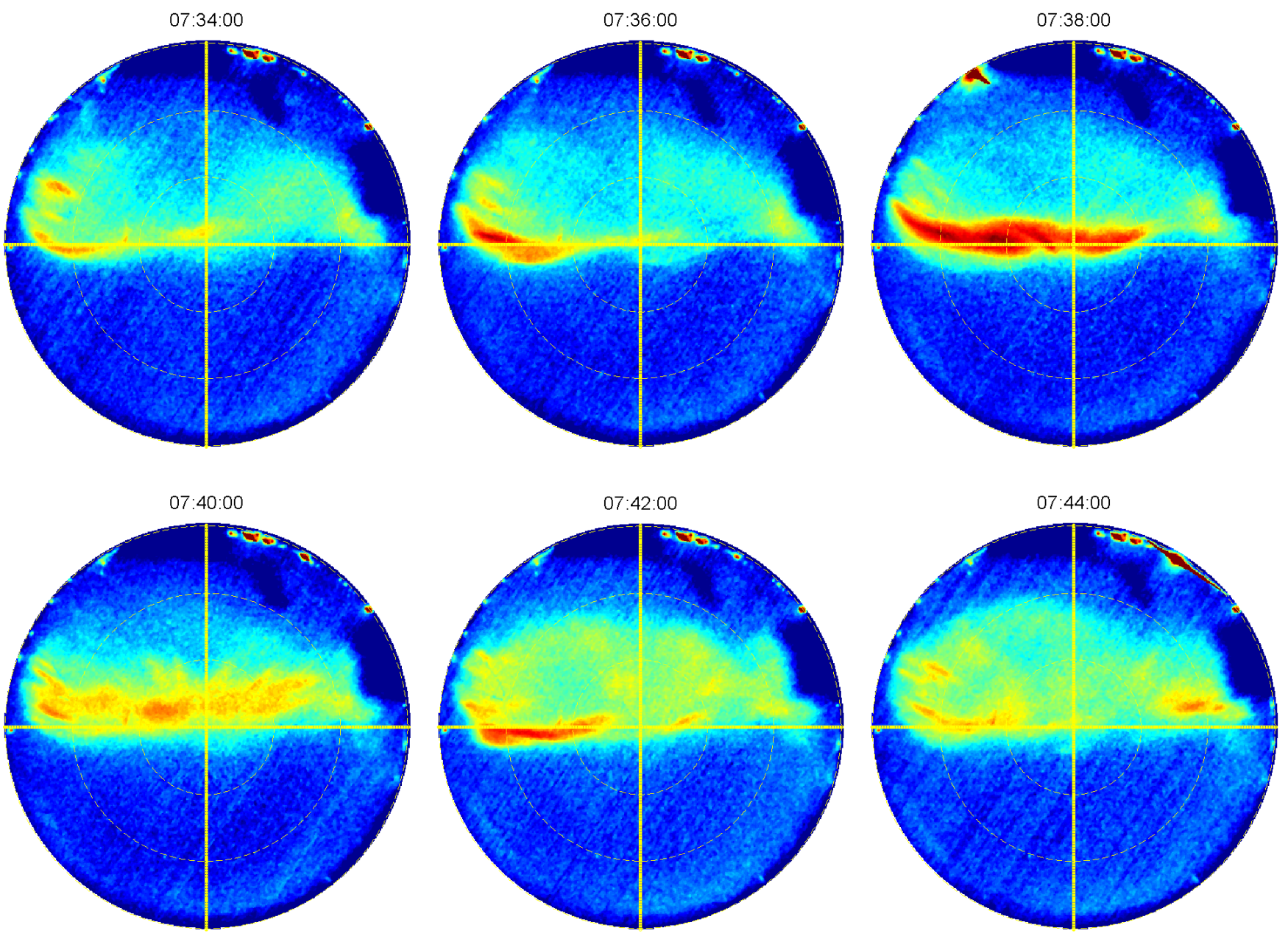

Fig. 5. ASC image sequence at $630.0 \mathrm{~nm}$ during the interval 07:34-07:44 UT. The coordinate system is zenth angle versus local azimuth. Zenith angles of 30,60 and $90^{\circ}$ are marked by dashed circles of increasing radius. The central vertical line marks the 11:00 MLT meridian. North is up and west is to the left. The image integration time is $2 \mathrm{~s}$.

expanding form reached the local meridian (11:00 MLT). In the interval 07:38-07:42 UT (lower row) this form expanded poleward and then configured as a relatively stable, extended form in the east-west dimension, crossing the Ny Ålesund meridian north of zenith, during 07:42-07:44 UT (the last two images).

Figure 6 shows ASC images at $630.0 \mathrm{~nm}$ obtained during the interval 08:40-08:50 UT. The central vertical yellow line marks the $\sim 12: 00$ MLT meridian. In the upper row $(08: 40-08: 44$ UT) we recognize the presence of bright forms on the eastern (right; postnoon) side of the local meridian ( 12:00 MLT). The much weaker auroral intensity on the western (prenoon) side of noon is the attenuated emission we refer to as "midday gap aurora." In the lower row (08:46-08:50 UT) we recognize the westward expansion of the postnoon activity. At 08:48-08:50 UT the bright forms extend equatorward to $30^{\circ} \mathrm{SZ}$ at the local magnetic meridian (see also MSP data in Fig. 3). A combination of Figs. 3 and 6 reveals the repetitive brightening/expansion of the postnoon activity (PMAFs/postnoon) during the interval 08:40-09:00 UT.

Figure 7 shows ASC images at $630.0 \mathrm{~nm}$ during the interval 09:15-09:25 UT. The central vertical yellow line marks the $\sim 12: 45$ MLT meridian. The approximate FOV of the ASC (in MLT/MLAT coordinates) at this time is marked by a circle in Fig. 1. The first image (upper left) shows the presence of elongated forms in the western (left) and eastern (right) parts of the FOV and weaker forms crossing the local magnetic meridian. Evident are the brightening and rapid westward (noonward) expansion of the postnoon (right side) forms during the interval 09:17-09:21 UT. At 09:21 UT the expanding form intersected the the local 

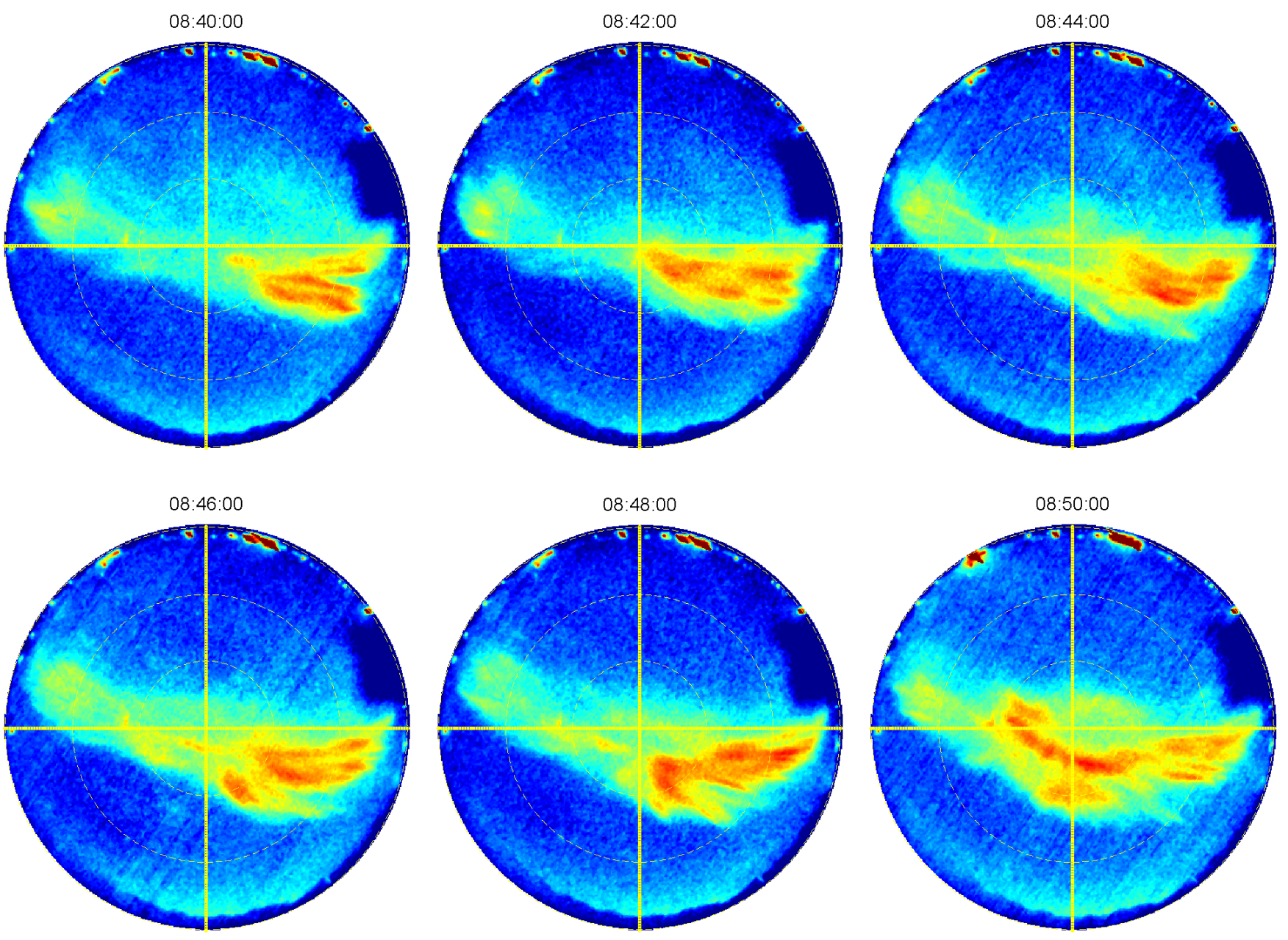

Fig. 6. ASC images at $630.0 \mathrm{~nm}$ during interval 08:40-08:50 UT. The central vertical line marks the $\sim 1200$ MLT meridian. Same format as in Fig. 5.

meridian ( $\sim 12: 45 \mathrm{MLT})$ at $\sim 40^{\circ} \mathrm{NZ}$ (see also Fig. 3). A fading of this form starting from its eastern (right) side part is seen during the interval 09:21-09:25 UT (lower row). A schematic illustration of the location of the bright highestlatitude form in MLT/MLAT coordinates is given by the heavy dashed line in Fig. 1.

\subsection{SuperDARN convection data}

We start with the presentation of SuperDARN background convection for the PMAFs/prenoon events in this case (07:50 UT).

Figure 8 shows SuperDARN convection data for the interval 07:50-07:52 UT (http://superdarn.jhuapl.edu). We notice a relatively good radar coverage in the region of the auroral observations (see double-arrowed line). SuperDARN (Greenwald et al., 1995) provides line-of-sight ve- locity measurements of the high-latitude ionosphere. These measurements are combined using the "Map Potential" fitting technique (Ruohoniemi and Baker, 1998) to produce maps of large-scale ionospheric convection.

Figure 8 indicates a weakly distorted 2-cell pattern. A westward (dawnward) convection component across noon is present in addition to the antisunward convection in the midday sector. We may also conclude that the PMAFs/prenoon (observed before 07:50 UT; see Fig. 3) belong to the dawncentered convection cell. These events are initially expanding noonward from an origin westward of the Ny Ålesund meridian (see Fig. 5). At 07:50 UT the zero-point potential line separating the dawn-centered and the dusk-centered convection cells lies in the close vicinity of the optical site in $\mathrm{Ny}$ Ålesund (marked by solid dot in the figure).

Figure 9 shows SuperDARN convection data for 08:4008:42 UT. In this case the radar coverage was also good in the 

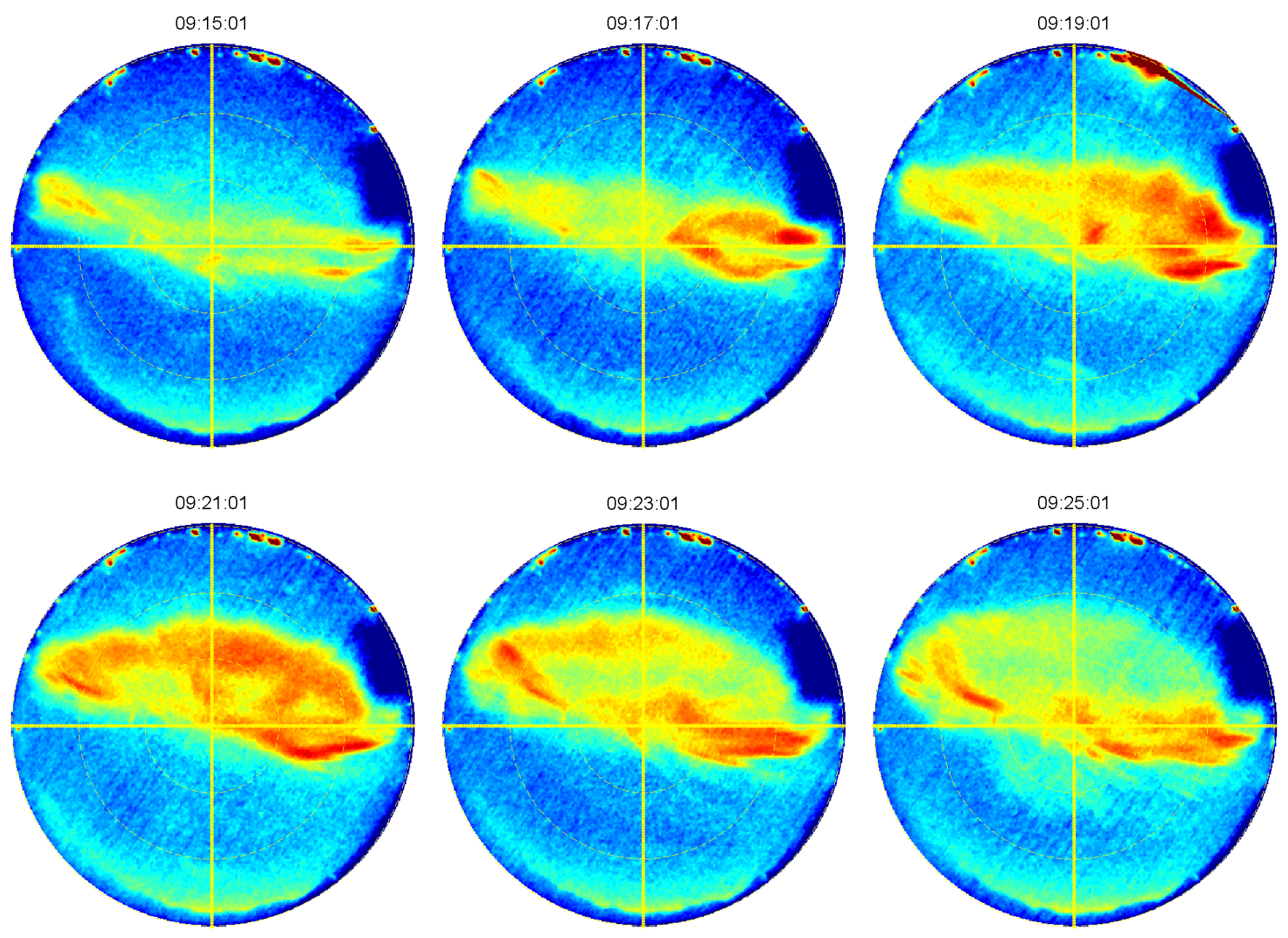

Fig. 7. ASC images at $630.0 \mathrm{~nm}$ during the interval 09:15-09:25 UT. The central vertical line marks the $\sim 12: 45$ MLT meridian. Same format as in Fig. 5.

sector of the Ny Ålesund auroral observations which is dominated by the dusk-centered (left) convection cell. A moderately distorted 2-cell pattern is indicated. PMAFs/postnoon (observed by the Ny Ålesund MSP after 08:40 UT; Fig. 3) belong to dusk-centered convection cell. As shown in Fig. 6 these events expand noonward, into the MSP FOV, from an origin eastward (duskward) of the Ny Ålesund meridian.

Figure 10 shows SuperDARN convection data for 09:2009:22 UT. A strongly distorted twin-cell convection pattern is observed near noon. It is characterized by the westward protrusion of the dusk-side convection cell. A channel of enhanced westward convection (shown in red) is observed in a belt located slightly poleward of Ny Ålesund. A region of strong flow shear is observed at the poleward boundary of this convection channel. This is the site of the bright, high-latitude auroral form appearing at 09:20 UT (see Fig. 3) which we identified as a type 3 PMAF. Thus, we may con- clude that this form belongs to the category of so-called flow shear arcs (Reiff et al., 1978).

\section{Observations on 4 December 1999}

\subsection{Case overview}

Here we report aurora-convection states under strong asymmetries induced by positive IMF $B_{y}$, and including the rapid response to a bi-modal IMF transition (southward turning followed by northward turning). The following auroraconvection states are encountered: (I) Cusp auroral brightening sequence and associated PMAFs/postnoon in distorted dusk cell during steady south-east IMF orientation $\left(\theta=130^{\circ}\right)$. (II) Cusp auroral intensification in response to southward turning (clock angle $\theta$ approaching $150^{\circ}$ ) and associated 


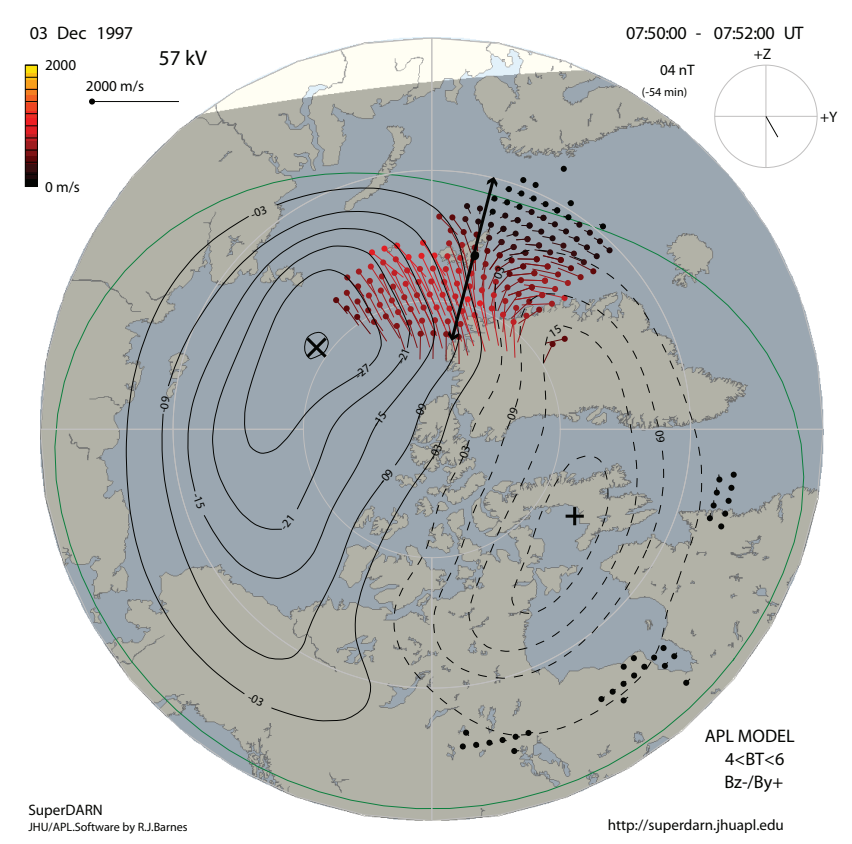

Fig. 8. SuperDARN convection data for 07:50-07:52 UT. Ion drift vectors and convection streamlines are shown in MLT/MLAT coordinates. MSP FOV at $630.0 \mathrm{~nm}$ is marked by double-arrowed meridional line. Ny Ålesund is marked by bold dot. 12:00 MLT is at the top. The perspective is looking down on the polar atmosphere with the magnetic pole in the center. Dawn is to the right.

dynamic pressure enhancement. (III) Rapid (1-2 min) transition to "double cusp" and flow shear arcs (FSAs) immediately poleward of the "northward IMF cusp" after the northward turning. The "double cusp" consists of a "southward IMF cusp" at reduced intensity, and the much brighter "northward IMF cusp". Bright green line polar arcs expanded westward (across the noon meridian) from the postnoon side. They appear in a region of strong flow shear at the poleward boundary of a convection channel at the cusp poleward boundary. Thus, this is a second example of flow shear arcs (Reiff et al., 1978) triggered by a northward turning of the IMF. In this case a DMSP pass crossed the cusp and its adjacent arcs and thereby documented the particle precipitation in the flow shear arcs.

\subsection{Wind interplanetary data}

Figure 11 shows plasma and magnetic field data obtained from spacecraft Wind during the interval 08:30-10:00 UT when Wind was located in the dawnside magnetosheath tailward of the terminator. Its average position was $(-42.1$, $-30.4,-12.0) R_{E}$ (GSE coordinates). This is a high speed stream where the proton density is varying between 10 $15 \mathrm{~cm}^{-3}$, a dynamic pressure changing between $5-10 \mathrm{nPa}$, and a magnetic field amplitude of 20-35 nT. IMF $B_{x}$ and $B_{y}$ are negative and positive, respectively, while $B_{z}$ (the northsouth component) changes from southward to northward at

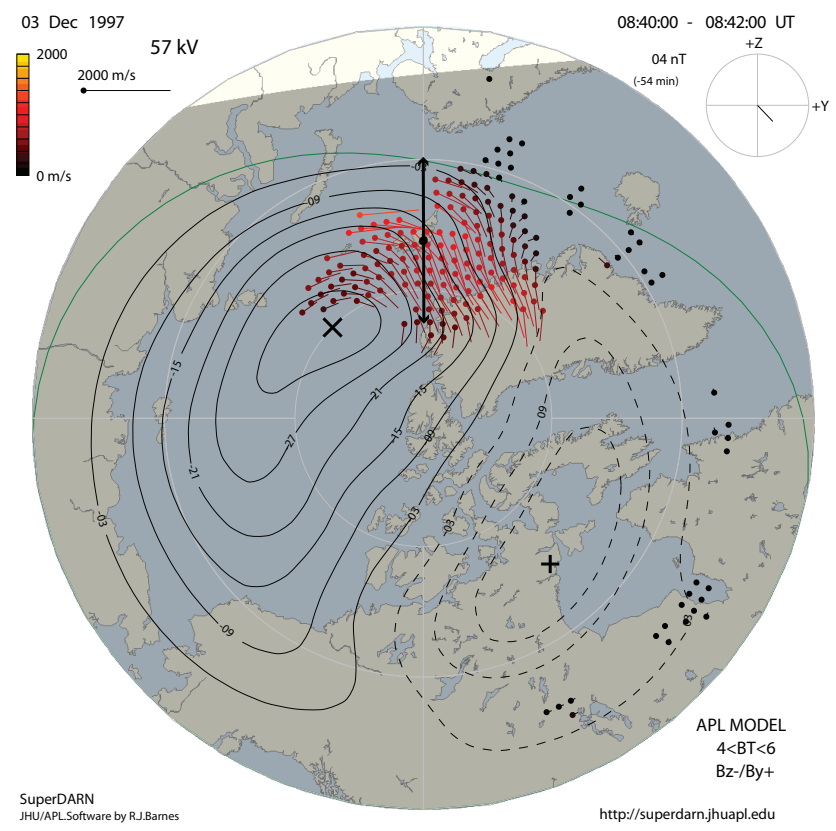

Fig. 9. SuperDARN convection data for 08:40-08:42 UT. Same format as in Fig. 8.

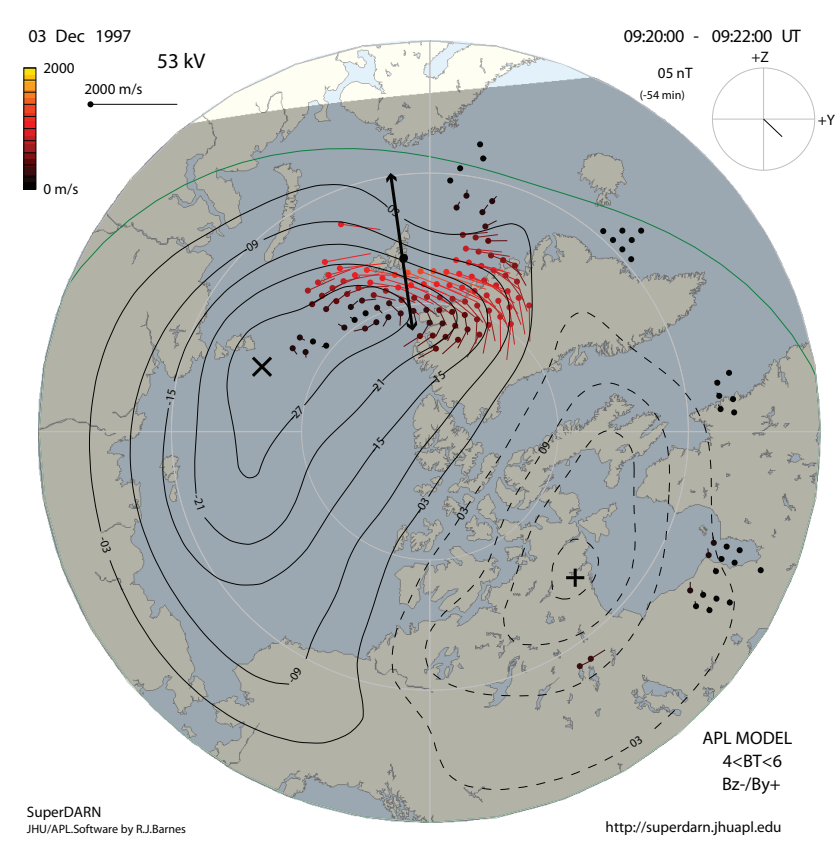

Fig. 10. SuperDARN convection data for 09:20-09:22 UT. Same format as in Fig. 8

09:19/19:20 UT. We shall focus on the four states in the intervals I-IV bounded by the vertical guidelines. Because of Wind's position and the high solar wind/magnetosheath speed we consider that the cusp region was affected by the solar wind/IMF changes practically simultaneously with their measurement at Wind or a few minutes earlier. 


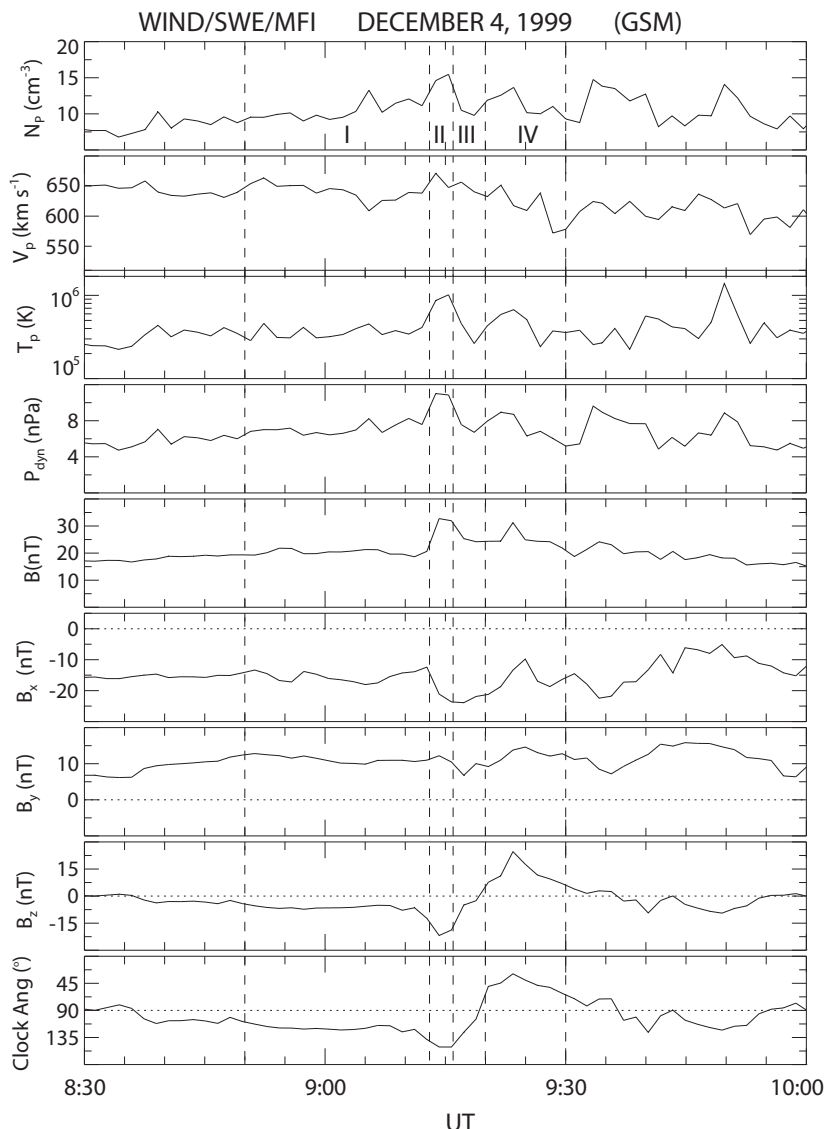

Fig. 11. Wind magnetic field and solar wind plasma data for the interval 08:30-10:00 UT. Panels from top to bottom shows proton density, temperature, bulk speed, dynamic pressure, the total magnetic field and its components $B_{x}, B_{y}$, and $B_{z}$. The bottom panel shows the IMF clock angle in the GSM Y-Z plane. Intervals of different magnetic field orientation are delimited by vertical guidelines.

Interval I (08:50-09:13 UT): stable, south-east magnetic field orientation (clock angle $(\theta)=120-135^{\circ}$ ). Interval II (09:13-09:16 UT): strongly south orientation $\left(\theta=150-160^{\circ}\right)$; enhanced density/dynamic pressure. Interval III (09:1609:20 UT): northward transition $(\theta$ decreasing from 160 $\left.45^{\circ}\right)$. Interval IV (09:20-09:30 UT): strongly northward field orientation $\left(\theta=40-50^{\circ}\right)$.

Below we shall study the aurora and plasma convection states corresponding to these intervals.

Figure 12 shows MSP data at two wavelengths $(630.0 \mathrm{~nm}$; $557.7 \mathrm{~nm}$ ) for 09:00-09:26 UT. We have:

Interval I (09:00-09:10 UT): Two brightenings centered at $50^{\circ} \mathrm{SZ}$ (red line emission).

Interval II (09:10-09:14 UT): Bright cusp (see green line emission). The red line maximum is a few min delayed with respect to the corresponding green line emission, a delay related to the time constant of the red line emission.

Interval III (09:14-09:16 UT): An attenuated cusp emission

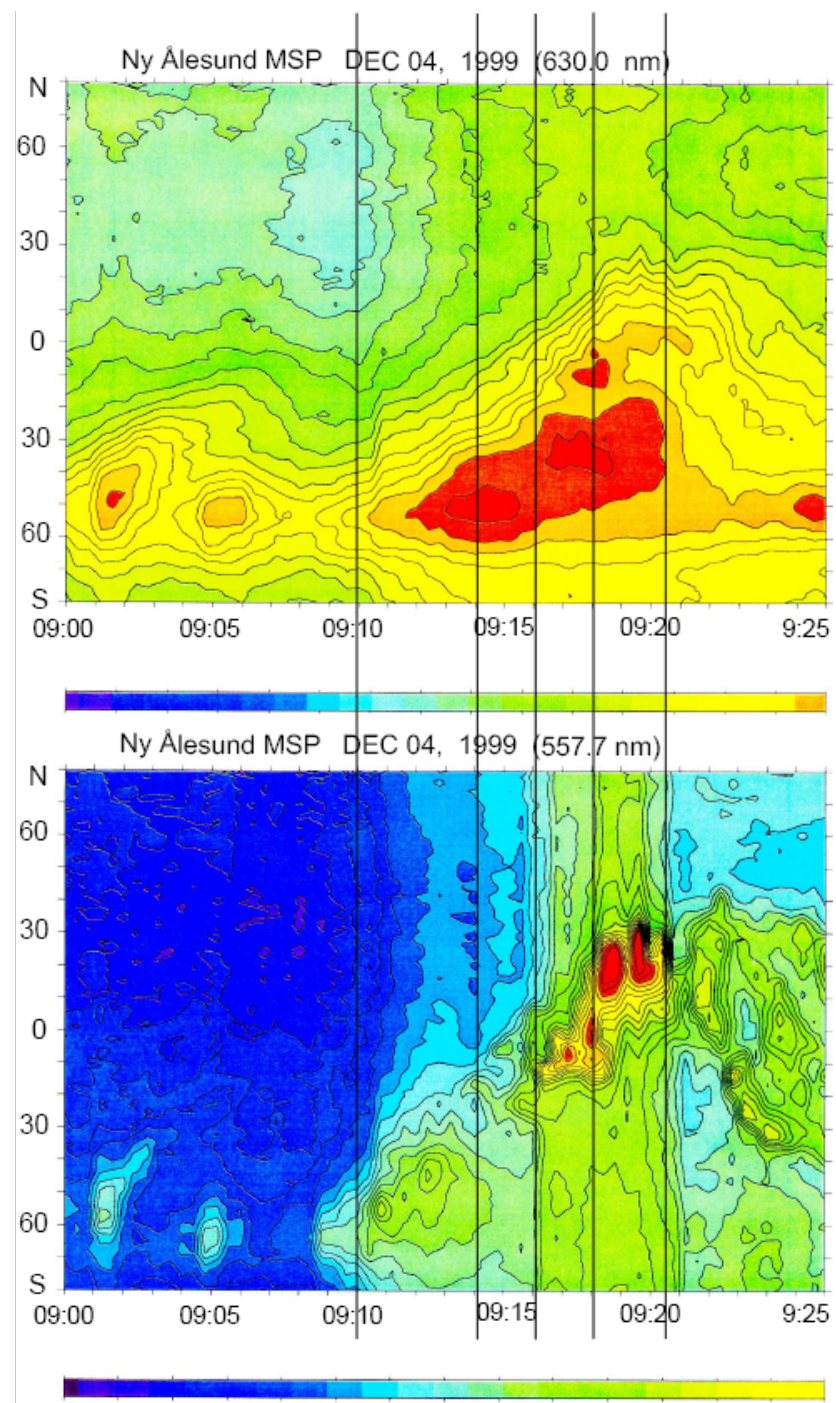

Fig. 12. Ny Ålesund MSP data (line-of-sight intensity versus zenith angle) during the interval 09:00-09:26 UT. The red and green line intensities are shown in the upper and bottom panels, respectively. Subintervals are marked by vertical guidelines.

(green line) is observed at the original position in this transition state.

Interval IV (09:16-09:20 UT): The auroral configuration consists of a double (latitudinally bifurcated) cusp aurora and polar arcs adjacent to the northernmost cusp component. The old (southward IMF) cusp appears at reduced intensity (at $50^{\circ} \mathrm{SZ}$ ) and the new (northward IMF) cusp (centered at 30 $40^{\circ} \mathrm{SZ}$; red line emission) appears at a high red line intensity (comparable to that of the previous southward IMF cusp). The poleward shift of polar arcs at 09:18 UT is also marked by vertical guideline. We note that the arcs appears strongly in the green line emission and that after 09:17 UT they are also present in the red line emission (near zenith). The difference in zenith angle location of the two emissions is due to 


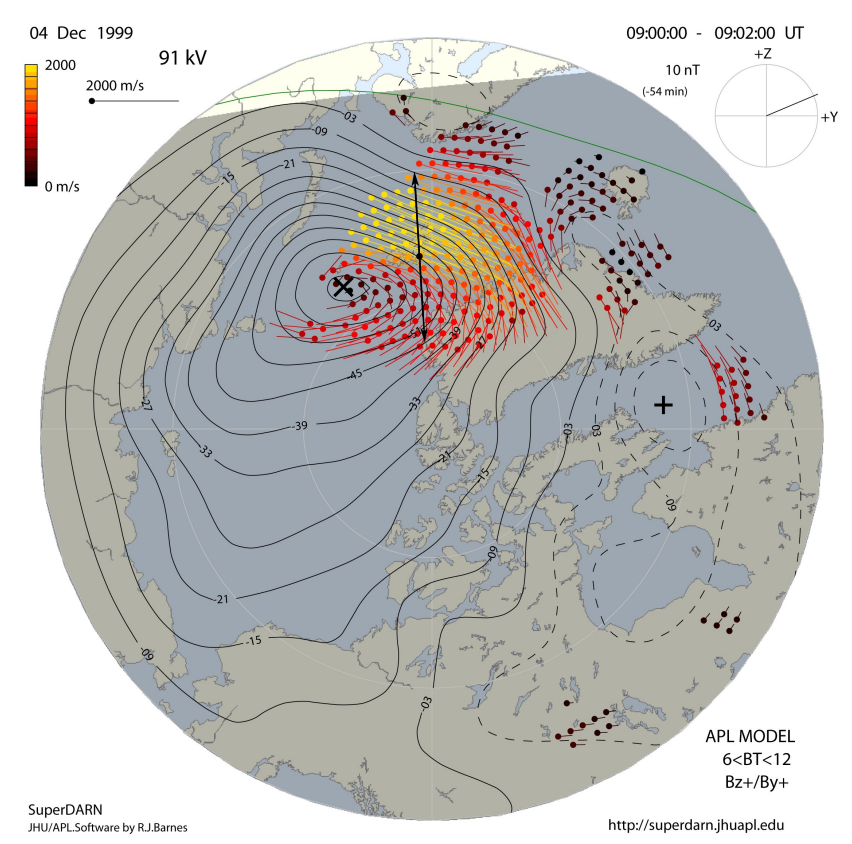

Fig. 13. SuperDARN convection data obtained during the interval 09:00-09:02 UT. Same format as in Fig. 8.

the different emission altitude. After 09:20 UT the polar arcs appear at much reduced intensity. This is accompanied by a fading and latitudinally narrowing of the local cusp (along the 12:45 MLT meridian). The observation geometry of the aurora in relation to plasma convection will be illustrated below at three times (before, under, and after the northward turning).

Figure 13 shows a spatial plot of the SuperDARN convection for 09:00-09:02 UT. We note the channel of enhanced westward convection (yellow arrows) in the latitude regime 72-76 ${ }^{\circ}$ MLAT in the 11:00-14:00 MLT sector. We note from Fig. 12 that one auroral brightening event maximized at 50 $\mathrm{SZ}(630.0 \mathrm{~nm})$ at 09:01-09:02 UT. This corresponds to $\sim 73^{\circ}$ MLAT, assuming an emission altitude of $250 \mathrm{~km}$ for the $630.0 \mathrm{~nm}$ transition line. We may conclude that the auroral emission at $\sim 72-75^{\circ}$ MLAT is colocated with the convection channel indicated (flow speed near $2 \mathrm{~km} / \mathrm{s}$ ) arrows in the SuperDARN plot. This auroral brightening and the following PMAF (approaching $75^{\circ}$ MLAT) is thus placed in the context of plasma convection. We document that this PMAF activity is associated with the distorted postnoon convection cell. Following the nomenclature of Sandholt and Farrugia (2007a) it is referred to as PMAF/ $B_{y}>0 /$ postnoon. Since no rebrightenings are observed, this corresponds to a type 1 PMAF in the classification of Fasel.

Figure 14 shows a SuperDARN spatial plot for 09:2009:22 UT. Compared to the previous (09:00 UT) convection state we can see the following changes: (i) reduced flow speeds in the postnoon sector (M-cell), (ii) a channel of enhanced westward-directed flow (yellow) has expanded west-

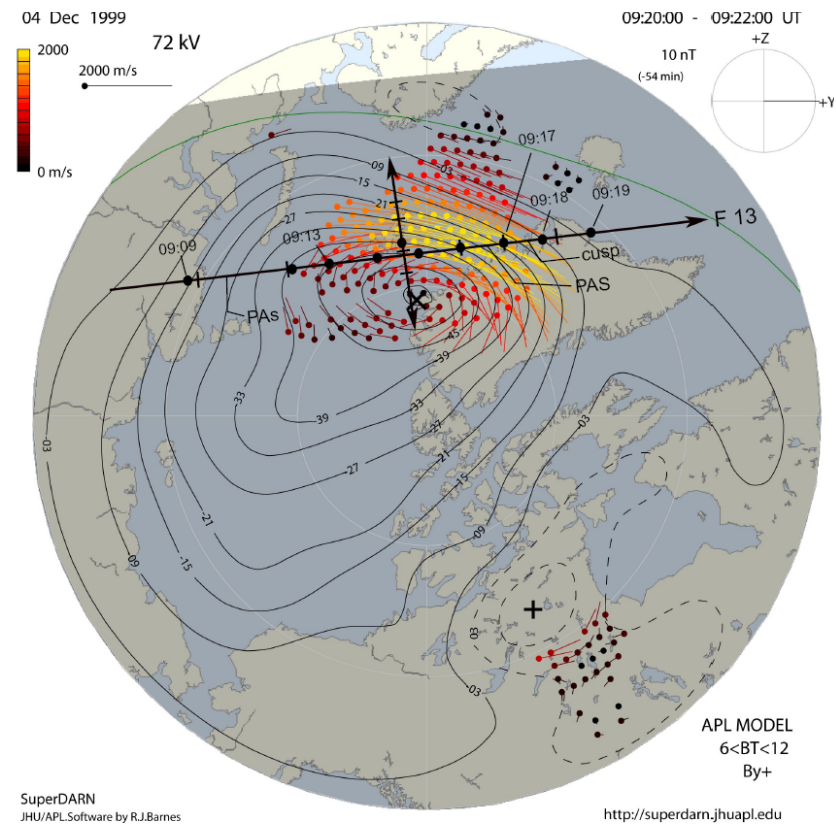

Fig. 14. SuperDARN convection data for 09:20-09:22 UT. Same format as in Fig. 8. The track of spacecraft DMSP F13 during the interval 09:09-09:19 UT has been overlayed. Precipitation regimes along the track are indicated. Latitudinally separate auroral forms have been marked along the Ny Ålesund MSP scanning meridian $(\sim 12: 40$ MLT).

ward and poleward, (iii) a flow shear at poleward boundary of the flow channel, marked negative poleward gradient, has also expanded to prenoon MLTs.

Three latitudinally separate auroral forms have been marked along the MSP scanning meridian at 09:20 UT (appr. 12:45 MLT). Proceeding from south to north these forms are (i) the "southward IMF cusp", (ii) the "northward IMF cusp", and (iii) the regime of polar arcs (see Fig. 12) located immediately north of Ny Alesund. The polar arc regime is characterized by a strong flow shear adjacent to the cusp poleward boundary. From standard current continuity requirement (Reiff et al., 1978) we may conclude that the corresponding converging electric field is accompanied by an upward-directed Birkeland current. Thus, the arcs appear in a region of flow shear and upward-directed Birkeland current.

The following precipitation regimes are detected by F13 during the interval 09:09-09:19UT: 09:09-09:12 UT: polar arcs (PAs), 09:12-09:16UT: polar rain (PR), 09:1609:17 UT: intensified polar arcs (PAs), 09:17-09:18:20 UT: cusp/LLBL-type, 09:18:20-09:21 UT: CPS-type. A channel of enhanced antisunward convection within $74-75^{\circ}$ MLAT is detected by F13 during the interval 09:17-09:18 UT. This flow channel is thus located equatorward of the convection channel detected by SuperDARN at 09:20-09:22 UT within $75-77^{\circ}$ MLAT (see yellow drift vectors). The mismatch 


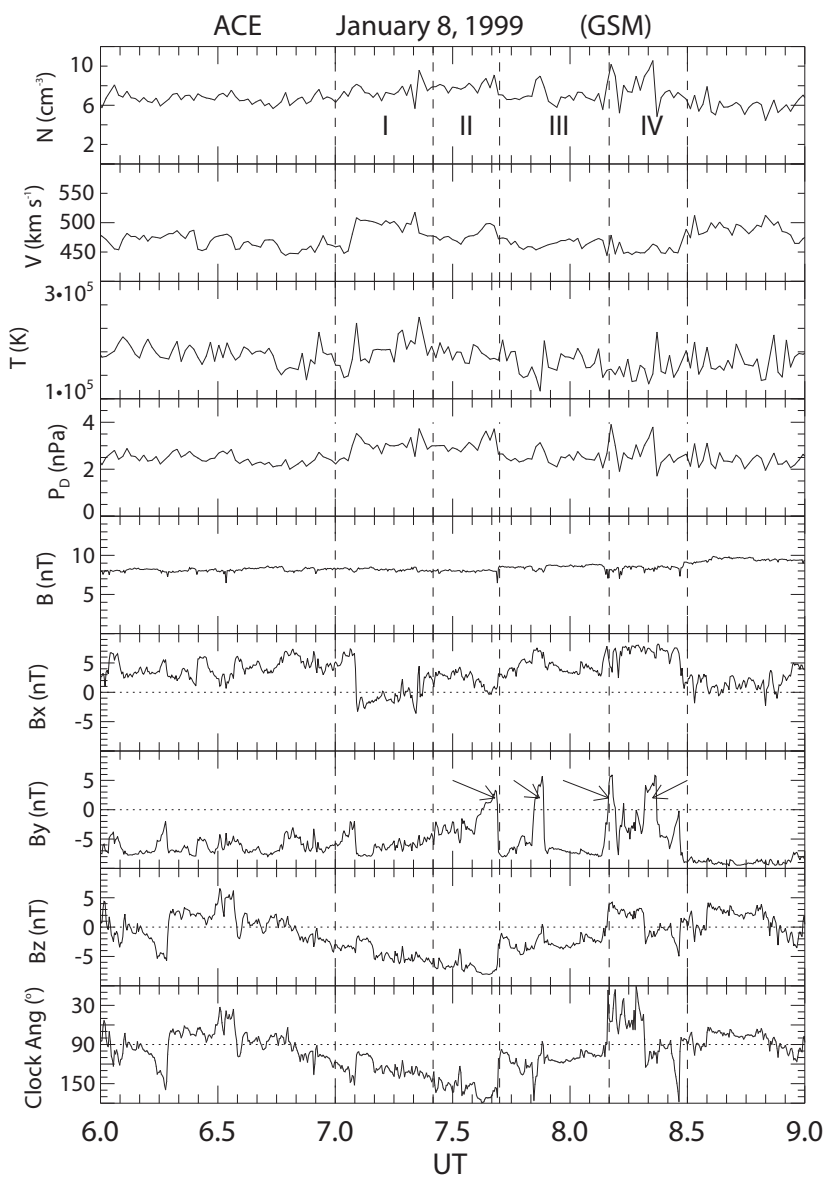

Fig. 15. ACE solar wind plasma and IMF data for the interval 06:00-09:00 UT. Panels show from top to bottom proton density, bulk speed, proton temperature, dynamic pressure, the total magnetic field and its components $B_{x}, B_{y}$, and $B_{z}$. The bottom panel shows the IMF clock angle. Subintervals are delimited by vertical guidelines. Abrupt changes of IMF $B_{y}$ polarity are marked by arrows.

between the F13 and the ground convection data is due to the poleward motion and latitudinal expansion of the convection channel during the interval between the two measurements (09:17-09:20/09:22 UT). A corresponding change is seen in the ground auroral observations in this interval (Fig. 12).

On the polar arc precipitation, as inferred from the ground and satellite data, we add the following remark. The polar arcs (PAs) observed by F13 in the postnoon sector (15:00-16:00 MLT) during 09:09-00:12 UT correspond to the interval immediately before the IMF northward turning $\left(\theta=120^{\circ}\right)$ while the intensified arcs observed prenoon (09:00-10:00 MLT) during 09:16-09:17 UT (from the same spacecraft) refer to the interval immediately after the northward turning. The intensified arcs appears in the ground data (at 12:30 MLT) at 09:15-09:16 UT. At 09:16 UT they are identified in the F13 electron precipitation data at 11.2 MLT/76. ${ }^{\circ}$ MLAT. From this information we conclude that the polar arcs which resided in the late postnoon-dusk sector (beyond the 15:00 MLT meridian; not seen by the MSP at 12:45 MLT) before the IMF transition (as observed by F13 during 09:09-09:12 UT) intensified and expanded rapidly westward during the interval 09:15-09:16 UT, thereby reaching the 11.2 MLT meridian at 09:16 UT (F13 data). The full discussion of the response to the northward turning of the IMF is presented in the discussion section. The F13 data obtained during the interval 09:13-09:22 UT have been reported by Sandholt et al. (2002b).

\section{Observations on 8 January 1999}

\subsection{Case overview}

Here we study the association of aurora and plasma convection as the station moved with the Earth through the 10:00-13:00 MLT sector under generally southwest $\left(B_{y}<0\right)$ conditions which are interrupted by brief pulses of $B_{y}>0$. Thus this interval is appropriate for the study of the auroraconvection state under generally stable $B_{y}<0$ conditions (clock angle range: $70-180^{\circ}$ ) on which are overlaid transients triggered by sharp $B_{y}$ polarity changes. We shall focus on the following three features of the spatio-temporal structure of the aurora - convection observations:

1. auroral activity (PMAFs/prenoon) involving three latitudinally separate precipitation regimes in the strongly distorted prenoon convection cell under steady southwest ( $B_{y}$-dominated) IMF orientation,

2. strongly attenuated aurora in the close vicinity of the zero-point potential line separating the prenoon and postnoon convection cells in a symmetrical 2cell convection configuration under strongly south $\left(B_{z^{-}}\right.$ dominated) IMF conditions, and

3. auroral activity (PMAFs/postnoon) in the distorted postnoon convection cell under disturbed IMF conditions consisting of precipitation transients (equatorward boundary intensifications) and channel of enhanced westward convection on open LLBL field lines and flow shear arcs appearing at higher latitudes, at the poleward boundary of the convection channel.

\subsection{ACE interplanetary data}

Figure 15 shows the solar wind plasma and IMF data obtained from spacecraft ACE during the interval 06:0009:00 UT. The average position of ACE was (229.3, 37.4, 3.6) $R_{E}$. During this interval (06:00-09:00 UT) the proton density, bulk speed, and dynamic pressure are fluctuationg around the following mean values: $7 \mathrm{~cm}^{-3}, 460 \mathrm{~km} / \mathrm{s}$, and $3 \mathrm{nPa}$. The amplitude of the IMF is stable at $8-9 \mathrm{nT}$. The $B_{x}$ and $B_{y}$ components are generally positive and negative, respectively. The negative $B_{y}$ interval is interupted by brief 
pulses of positive $B_{y}$ at 07:40, 07:50, 08:10, and 08:20 UT. A continuously increasing negative $B_{z}$ component $(0--7 \mathrm{nT})$ is observed between 06:50-07:42 UT. This interval we shall divide in two subintervals corresponding to the two clock angle regimes $110-150^{\circ}\left(B_{y}\right.$-dominated interval I) and 150 $180^{\circ}\left(B_{z}\right.$-dominated interval in the figure). During interval III (07:42-08:09 UT) the negative $B_{y}$ is the major component $\left(B_{z}\right.$ is only slightly negative; $\left.\theta=100-130^{\circ}\right)$. Interval III is interrupted by a brief $B_{y}$ positive pulse and enhanced plasma density/dynamic pressure at 07:50-07:53 UT. During interval IV (08:10-08:30 UT) both the $B_{z}$ and $B_{y}$ components are fluctuating. The two brief pulses of positive $B_{y}$ at 08:09-08:12 and 08:19-08:22 UT are accompanied by pulses of enhanced proton density/dynamic pressure.

So, we distinguish between four IMF states/regimes:

1. 07:00-07:25 UT: southwest IMF (clock angle range = $\left.110-150^{\circ}\right)$;

2. 07:25-07:42 UT: strongly south IMF orientation (clock angle range $=150-180^{\circ}$ ) followed by rapid northward transition at 07:42 UT,

3. 07:42-08:09 UT: $B_{y}$-dominated (southwest) IMF orientation (clock angle range $=90-120^{\circ}$ ) interrupted by one brief pulse of positive $B_{y}$,

4. 08:09-08:30 UT: strongly fluctuating IMF orientation with positive and negative $B_{z}$ and $B_{y}$ values being realized.

Applying a solar wind speed of $460 \mathrm{~km} / \mathrm{s}$ and also including a dynamic pressure of $3 \mathrm{nPa}$ to get the magnetopause position and the slowing down of the speed in the magnetosheath, we obtain an ACE-to-magnetopause propagation delay of $55 \mathrm{~min}$. This is useful information when we relate the solar wind plasma and IMF conditions to observations of the dayside aurora.

\subsection{Auroral observations}

Figure 16 shows MSP data at two wavelengths (630.0 and $557.7 \mathrm{~nm}$ ) obtained during the interval 08:10-09:40 UT (11:40-13:10 MLT). We shall focus on the following features: (i) prenoon sector activity at 08:10-08:25 UT (11:4011:55 MLT), (ii) aurora at reduced intensity ("midday gap" or "midday minimum") during 08:25-08:52 UT (11:5512:27 MLT), and (iii) postnoon auroral activity during 08:5209:40 UT (12:27-13:10 MLT). Representative examples of the plasma convection states (SuperDARN data) during the times 08:20, 08:40, 09:20, 09:30, and 09:40 UT (see vertical guidelines) will be given below. Interval (i) is characterized by the presence of three latitude regimes of different auroral forms. The pulsating diffuse, green line aurora in the south (absent in the red line) is detached from the major discrete forms in the range $30^{\circ}$ SZ-zenith in the green line emission (MLAT range 74-76 ${ }^{\circ}$ MLAT). Brightenings
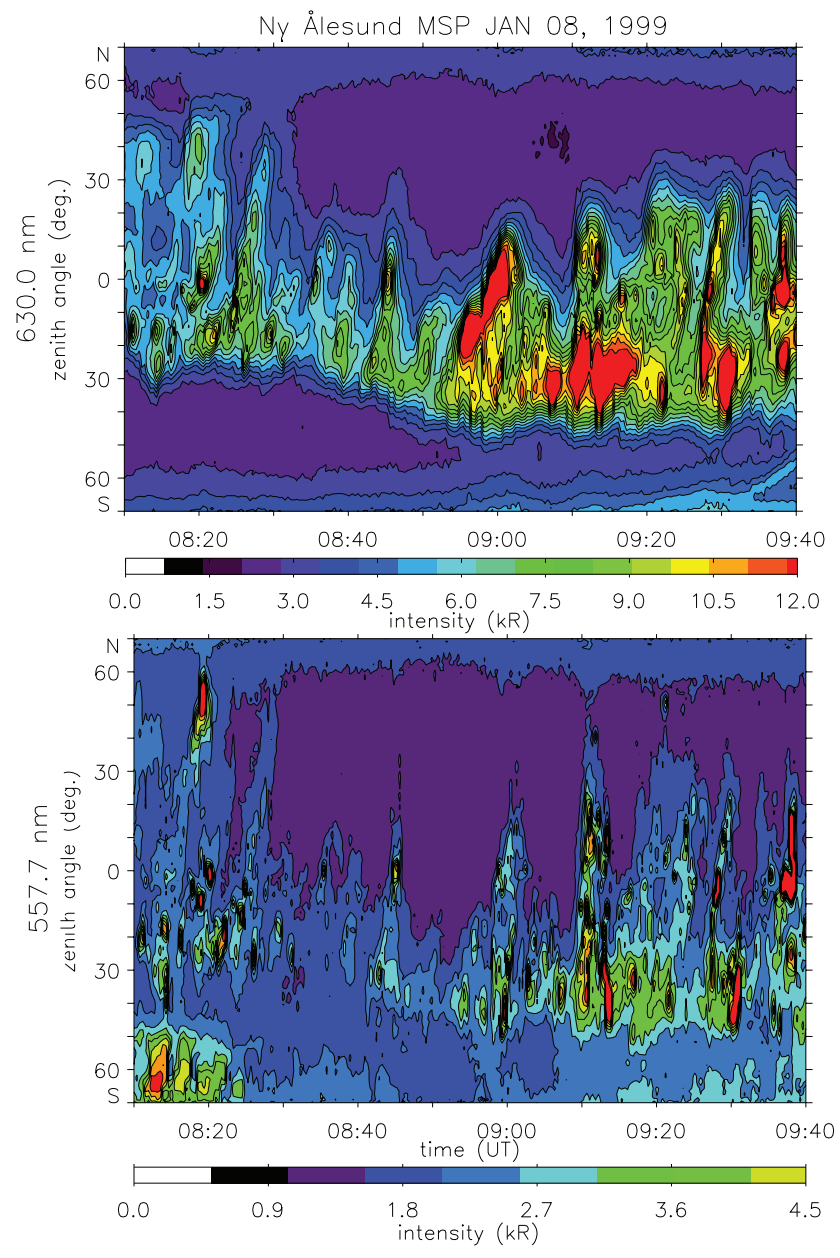

Fig. 16. Ny Ålesund MSP data for the interval 08:10-09:40 UT. The red and the green line emissons are shown in the upper and lower panels, respectively. Times of SuperDARN plasma convection data shown in this study are indicated by vertical guidelines. Same format as in Fig. 3.

in the latter regime are seen to expand from lower (SZ) to higher (NZ) latitudes (PMAFs) and sometimes (see 08:1408:20 UT) "rebrightenings" appear well to the north of the station (appr. $78^{\circ}$ MLAT). Thus, the 08:14-08:20 UT event is identified as a type $2 \mathrm{PMAF} /$ prenoon $/ B_{y}<0$.

Interval (ii) from 08:25-08:52 UT is characterized by a strongly attenuated emission intensity at both wavelength channels. In interval (iii) from 08:52-09:40 UT the red line emission is more intense than in the prenoon interval. Brightenings are seen in two latitudinally separate bands $\left(15-40^{\circ}\right.$ $\mathrm{SZ}$ and $10^{\circ} \mathrm{SZ}-20^{\circ} \mathrm{NZ}$ in the red line). In some of these cases brightenings are propagating from lower to higher latitudes, crossing station zenith. These latter events are categorized as type $2 \mathrm{PMAFs} /$ postnoon $/ B_{y}<0$. Below we shall report SuperDARN plasma convection data representing the four times marked by the vertical gudelines in Fig. 16. 


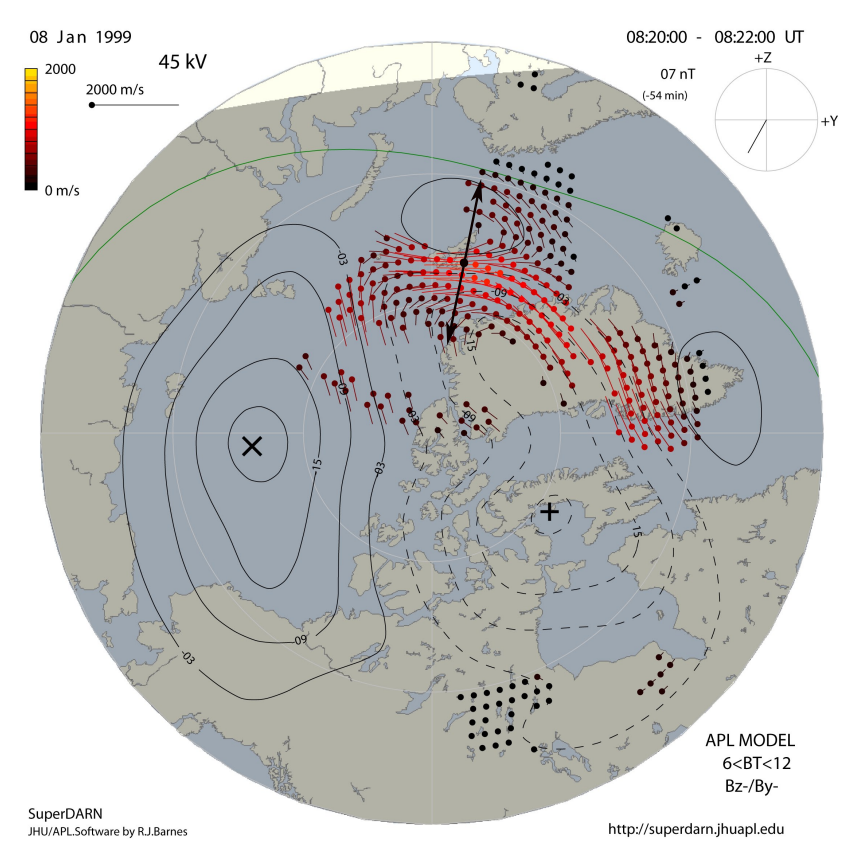

Fig. 17. SuperDARN convection data for 08:20-08:22 UT. Same format as in Fig. 8.

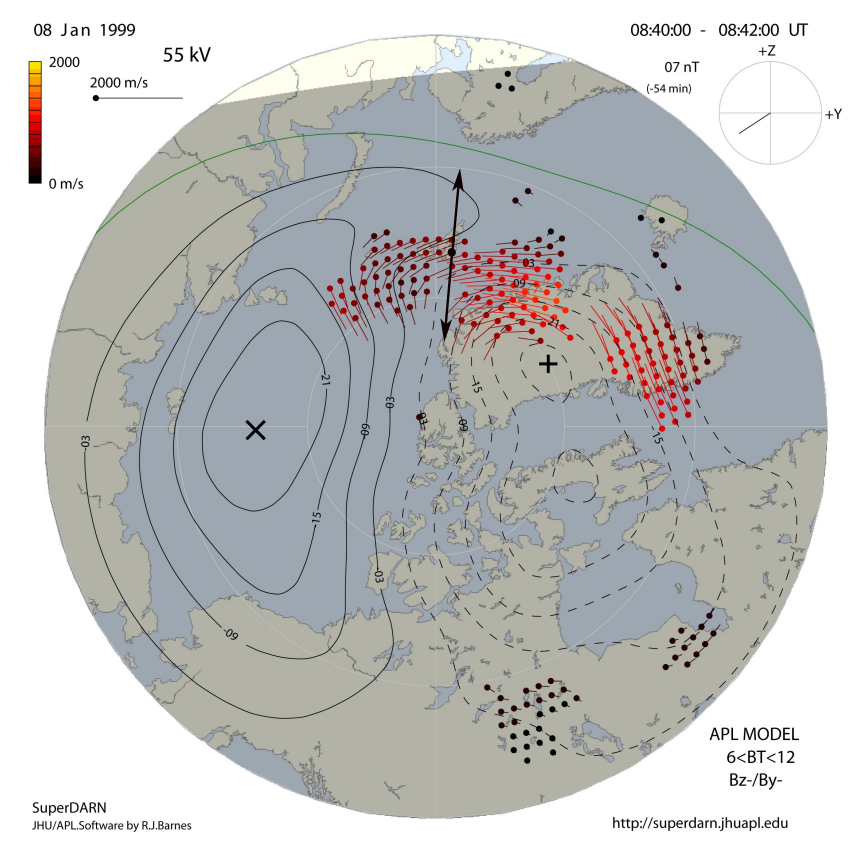

Fig. 18. SuperDARN convection data for 08:40-08:42 UT. Same format as in Fig. 8.

\subsection{SuperDARN convection data}

Figure 17 shows the northern part of the MSP FOV located in a region of strongly distorted prenoon convection cell consistent with the prevailing negative IMF $B_{y}$ polarity. A channel of enhanced eastward convection extends from prenoon

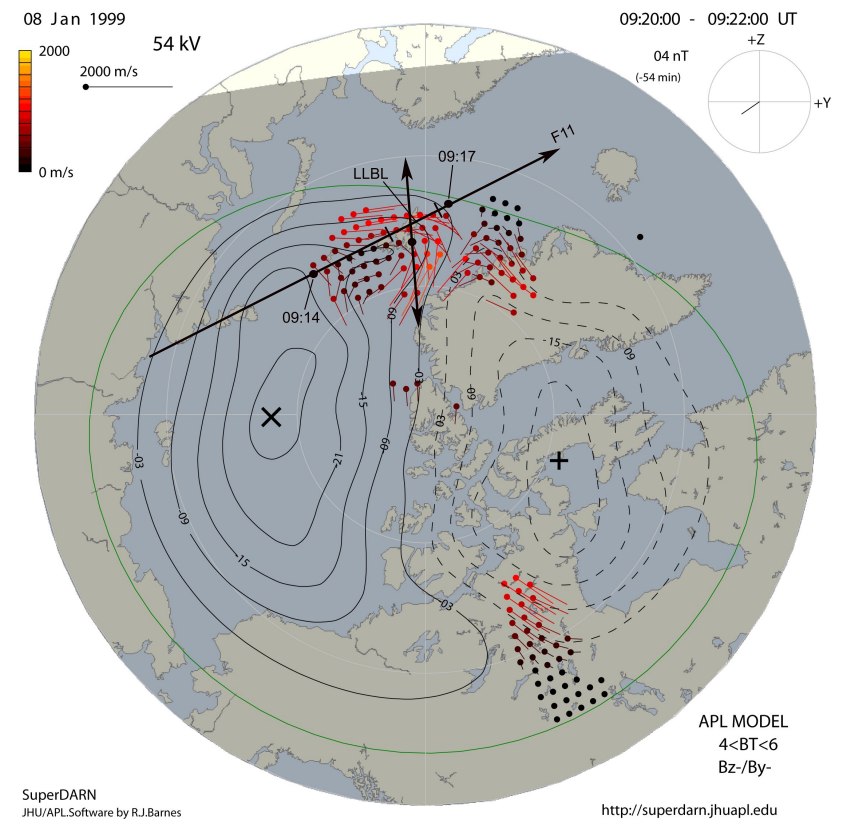

Fig. 19. SuperDARN convection data for 09:20-09:22 UT. Same format as in Fig. 8.

to postnoon longitudes. The convection vectors turns northward at the poleward boundary of this flow channel.

We recall the auroral observations in Fig. 16 which showed different auroral forms covering a wide range of latitudes (type 2 PMAFs/prenoon). The bright discrete aurora within 74-76 ${ }^{\circ}$ MLAT coincides with the equatorward boundary of the convection channel. PMAFs extending to higher latitudes (76-78 MLAT) occur in the region of a significant poleward convection component.

Figure 18 shows a more symmetrical convection configuration with the MSP FOV being located near the zero-point potential line between the convection cells. Recalling the MSP observations of the aurora in Fig. 16 we do see that this MLT sector is characterized by a strongly reduced auroral intensity during an interval of strongly south IMF orientation (clock angle $\theta \geq 150^{\circ}$ ). This auroral regime we identify as the so-called "the midday gap aurora."

Figure 19 shows the MSP FOV located in the postnoon convection cell (near the flow reversal). The local plasma convection turns from westward on the equatorward side of the station, within the range $74-75^{\circ}$ MLAT, to northeastward poleward of the station, within $76-80^{\circ}$ MLAT. The track of spacecraft DMSP F11 during the interval 09:14-09:17 UT is overlayed. The precipitation data from the satellite shows that the plasma flow channel in the midday sector is colocated with LLBL type precipitation (Sandholt et al., 2002a). The LLBL interval is delimited by two bars along the F11 trajectory (09:15:30-09:17:00 UT). This tells us that the auroral brightening events observed slightly south of zenith in this case were caused by magnetosheath type precipitation 


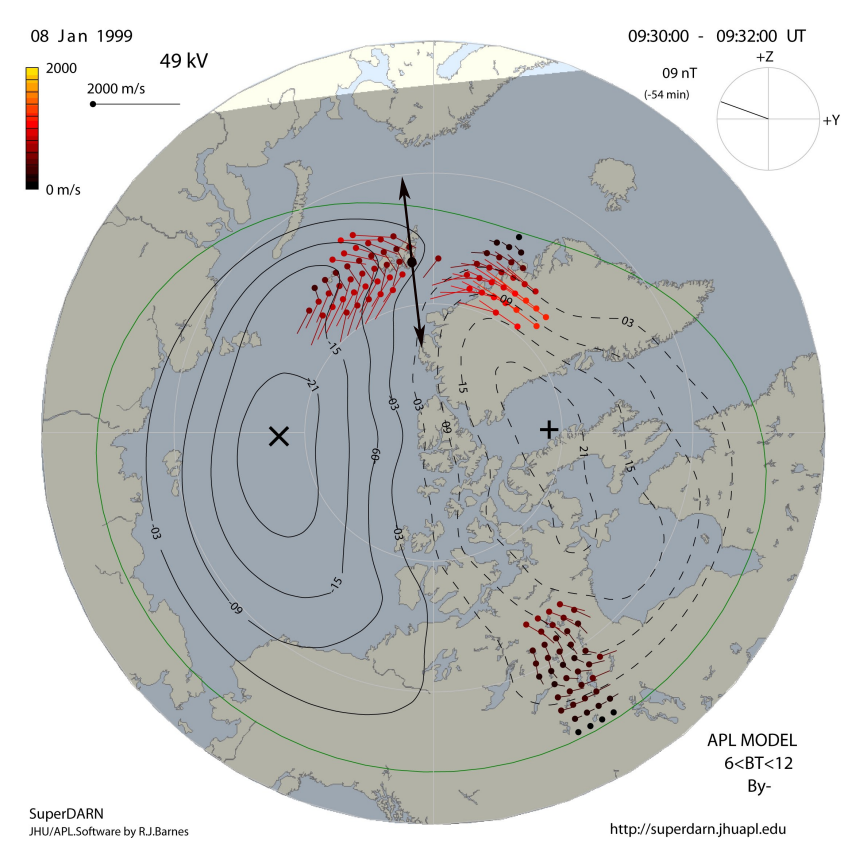

Fig. 20. SuperDARN convection data for 09:30-09:32 UT. Same format as in Fig. 8.

located on open LLBL field lines. PMAFs extending to higher latitudes (beyond the zenith of the station) occur in a regime of large northeastward convection. The clockwise flow vorticity at this locale is consistent with the presence of Birkeland current directed out of the ionosphere.

Figure 20 shows SuperDARN convection data for 09:3009:32 UT. The convection in the zenith of the optical site is characterized by strong clockwise vorticity in the postnoon convection cell. This is the site of the rebrightenings in the type 2 PMAFs observed at this time (Fig. 16).

Figure 21 shows SuperDARN convection data for 09:4009:42 UT. We note the presence of a strongly distorted 2-cell pattern. A channel of enhanced eastward convection (consistent with the steady $B_{y}<0$ conditions detected by ACE) is seen in the postnoon sector, within the latitude range 76$80^{\circ}$ MLAT. The optical site (at appr. 12:30 MLT) is colocated with the equatorward boundary of the eastward-directed flow channel. This is the site of strong clockwise vorticity where intense outward-flowing Birkeland current sheets are expected to be present. Transient auroral forms (type 2 PMAFs/postnoon) are seen in this same region (Fig. 16).

\subsection{Summary of observations}

We distinguish between four IMF states and the corresponding categories of plasma convection and auroral morphology in the 10:00-14:00 MLT sector.

IMF state I (07:00-07:25 UT; $\left.B_{y}<0, B_{z}<0, \theta=110-150^{\circ}\right)$ is associated with prenoon aurora consisting of latitudinally separate precipitation regimes (diffuse aurora in south and PMAFs/prenoon expanding across the zenith of the station)

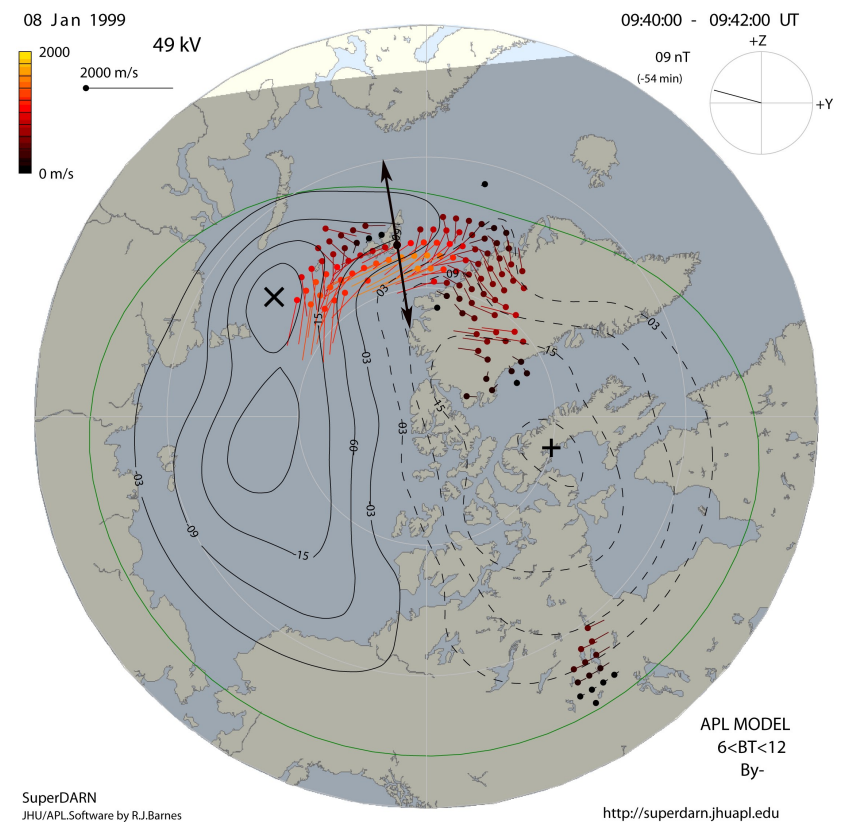

Fig. 21. SuperDARN convection data for 09:40-09:42 UT. Same format as in Fig. 8.

and a strongly asymmetrical 2-cell convection pattern. The auroral activity (PMAFs/prenoon events) is associated with the distorted prenoon convection cell) during the interval 08:10-08:25 UT.

IMF state II (07:35-07:42 UT; strongly south orientation; $\theta=150-180^{\circ}$ ) corresponds to an auroral emission band at much reduced intensity near noon (08:25-08:42 UT) and the establishment of a rather symmetrical two-cell convection pattern (see 08:40 UT SuperDARN data). Except for the transient event at 07:42 UT the strongly attenuated aurora prevails until 08:52 UT.

IMF state III (07:42-08:09 UT; $B_{y}$-negative dominated except for one brief $B_{y}$ positive pulse; $\theta=100-130^{\circ}$ ) corresponding to auroral brightening events in the distorted postnoon convection cell during 08:53-09:10 UT.

IMF state IV (08:09-08:30 UT; $B_{x}>0 ; B_{y}$ and $B_{z}$ fluctuations; $\theta=30-120^{\circ}$ ) corresponding to auroral brightenings in two separate latitude regimes in a strongly distorted postnoon convection cell. The equatorward boundary intensifications are pulses of LLBL precipitation on newly open field lines (see the DMSP F11 data at 09:17 UT reported by Sandholt et al., 2002a). The subsequent brightenings located at higher latitudes (PMAFs/postnoon) are identified as FSAs triggered by plasma flow transients (see SuperDARN data at 09:20 UT).

IMF state V (08:30-09:00 UT; $B_{y}=-9 \mathrm{nT}, B_{z}=0-3 \mathrm{nT}$; $\theta=70-90^{\circ}$ ) corresponding to two latitudinally separate auroral bands and strongly $B_{y}$-distorted (asymmetric) convection cells (eastward directed flow channel; see SuperDARN data at 09:40 UT) from 09:30 UT onwards. 
We note that IMF intervals I, III and V are similar (strongly negative $B_{y}$ ) while intervals II (strongly south) and IV (strongly fluctuating $B_{y}$ ) are different. This is reflected in basically three different aurora/convection states.

\section{Discussion}

Using cases studies on three different days, we investigated plasma convection in the 09:00-14:00 MLT sector in relation to PMAFs. The aurora consists of prenoon and postnoon activities separated by a limited band around noon where the auroral intensity is strongly attenuated. Thus, the observed auroral configuration (PMAFs/prenoon, midday gap, PMAFs/postnoon) and the auroral motion pattern in relation to plasma convection channels are similar to that envisaged by Kan et al. (1996). The IMF $B_{y}$ effects were not considered by Kan et al. (1996). The focus in this paper is on the auroral transients in the pre- and postnoon sectors in relation to dawn-dusk asymmetric plasma convection cells induced by IMF $B_{y}$. We find that auroral transients are triggered by IMF transitions ( $B_{y}$-pulses/fluctuations and northward turnings) and/or solar wind dynamic pressure enhancements. PMAFs/prenoon and PMAFs/postnoon consists of brightenings appearing in 2-3 different latitude regimes. In the past these events have been referred to as "multiple brightening PMAFs" (Fasel, 1995). It has been shown in case studies that the initial, most equatorward brightenings occur in the latitude regime of LLBL-type precipitation, on newly open field lines (Sandholt et al., 2002a). A second brightening may occur in the region of flow shear and upward-directed Birkeland current as depicted in the Southwood model of the ionospheric signature of FTEs (Southwood, 1987; Sandholt et al., 1990). This dual brightening is observed during steady IMF and solar wind conditions (Sandholt and Farrugia, 2007a). In this paper we investigate the role of flow shear at the ionospheric level under unsettled IMF and solar wind conditions. It has been suggested that transient variability in the IMF $B_{y}$ component should lead to so-called flow shear arcs in the dayside aurora (Newell and Sibeck, 1993). First we discuss the equatorward boundary intensifications (EBIs). After that we shall consider the higher-latitude transients including those we call poleward boundary intensifications (PBIs), located in the close vicinity of the cusp.

Good examples of EBIs in our observations are the prenoon $/ B_{y}>0(07: 35-07: 38 \mathrm{UT})$ and postnoon $/ B_{y}>0$ (08:40-09:00 UT) events on 3 December 1997 (see Fig. 3) and the postnoon $/ B_{y}$ fluctuating (09:10-09:20 UT) events on 8 January 1999 . In some cases, particularly in the prenoon sector, intense BPS-type arcs associated with upwarddirected Birkeland currents are observed at the equatorward edge of the open LLBL (Sandholt and Newell, 1992).

The prenoon $/ B_{y}>0$ EBI on 3 December 1997 (07:3507:38 UT) is connected with the dawn-centered convection cell. This brightening event, appearing at $76^{\circ}$ MLAT, ex- pands noonward (eastward) along the equatorward edge of a channel of enhanced eastward convection. Thus, it is located in a region of flow shear at the equatorward edge of the eastward (noonward)-directed convection channel and related upward-directed Birkeland current. The subsequent poleward expansion followed by a more stationary high-latitude aurora is an example of category 3 PMAFs (Fasel, 1995).

On 8 January 1999 EBIs are observed in the prenoon (08:10-08:30 UT) and postnoon (09:00-09:40 UT) sectors. In the former case the auroral brightenings occur in a latitude regime (74-75 ${ }^{\circ}$ MLAT) of strong clockwise flow vorticity in the strongly distorted dawn-centered convection cell documented in Fig. 17.

The EBIs in the postnoon sector (09:00-09:40 UT) are located at the equatorward boundary of the channel of enhanced westward (noonward) convection, slightly equatorward of the optical site in Ny Ålesund, as seen in Figs. 19, 20 and 21. The IMF $B_{y}$-induced dawn-dusk convection asymmetry (distortion) is particularly strong in the 09:40 UT case corresponding to IMF $\left|B_{y} / B_{z}\right|>1$ conditions. As documented by the DMSP F11 data during a pass at 09:1609:17 UT (Fig. 19) the EBIs in this case correspond to newly open LLBL field lines (Sandholt et al., 2002a).

Next we discuss the auroral brightenings appearing in the poleward part of the cusp precipitation (mantle) which we call PBIs. These consist of PMAF rebrightenings of type 3 according to the classification of Fasel (1995). We document that the most intense brightenings (particularly strong in the green line emission) of this type occur in regions of high flow shear associated with transient distortions of plasma convection cells during IMF $\left|B_{y} / B_{z}\right|>1$ conditions, and thus with intense Birkeland current sheets. This interpretation in terms of flow shear arcs (FSAs) is most easily applicable to the strongly distorted dusk-centered convection cells appearing during positive IMF $B_{y}$ conditions. According to Frey et al. (2004) such high-latitude dayside arcs (HiLDAs) "shows a maximum in the Northern Hemisphere during sunlit summer months and an almost complete absence in the dark winter." Representative examples of winter PBIs are the 09:20 UT brightening arcs observed in both $B_{y}>0$ cases reported here (3 December 1997 and 4 December 1999). Both events were triggered by northward turnings of the IMF giving rise to westward/noonward expansions of dusk-centered convection cells. Even during steady southeast IMF orientation $\left(\theta \sim 135^{\circ}\right)$ the same type of polar arcs (FSAs) are observed in the postnoon/dusk sector, beyond the 14:00 MLT meridian (Sandholt et al., 2006). We document that these polar arcs intensify and expand westward (across the 12:00 MLT meridian) in close association with the strongly distorted duskcentered convection cells appearing in response to northward turnings of the IMF. The arcs are excited by precipitation of $\sim 1-5 \mathrm{keV}$ electrons located at the poleward boundary of a channel of enhanced westward convection and the associated cusp-type precipitation (see Sandholt et al., 2002a, and Fig. 14). 
The convection/precipitation geometry in the case of the eastward-directed IMF $\left(\theta=90^{\circ}\right)$ on 3 December 1997 is schematically illustrated in Fig. 1. The plasma flow indicated by the red streamlines in this figure is the background convection pattern with dawn-centered and dusk-centered convection cells taken from Figs. 8 and 9 plus the flow transient (FSA) which was activated around 09:20 UT (Fig. 10). The FSA is marked by the heavy dashed line in the figure. We argue that in both cases (3 December 1997 and 4 December 1999) the postnoon cell expanding noonward (activated by the northward turning) is a lobe cell triggered by lobe reconnection (Eriksson et al., 2003; Sandholt and Farrugia, 2006). The 4 December case (Figs. 13 and 14) shows sunward convection at high latitudes in the postnoon sector as expected for a lobe cell under $B_{y}>0$ conditions (Eriksson et al., 2005).

Then we move to the case of multiple brightenings on 8 January 1999 (case 3) when a generally negative IMF $B_{y}$ was interupted by short intervals of positive $B_{y}$. We shall discuss one clear prenoon event (08:20UT) and the postnoon events during the interval 09:00-09:40 UT (Fig. 16). The prenoon event is a strong (see green line intensity) type 2 rebrightening form located at $78^{\circ}$ MLAT, associated with a $B_{y}$-distorted dawn-centered convection cell. IMF $B_{y}$ was stable and negative at this time (Fig. 15). The auroral form is located at the poleward boundary of the westward-directed flow channel documented in Fig. 17. Here the plasma flow is directed westward and poleward. In the absence of flow shears no Birkeland currents are expected, and we thus conclude that this event is of a different category than those discussed above.

The postnoon events (09:00-09:40 UT) are type 2 brightenings located close to the station zenith. According to SuperDARN (Figs. 19, 20, and 21) this is a region of strong clockwise flow vorticity in the distorted dusk-centered convection cell. This is consistent with upward-directed Birkeland current. Thus, these events belong to the category of flow shear arcs (FSAs). These events are driven by transients, chiefly in IMF $B_{y}$ (see arrows in Fig. 15) and the plasma flow disturbances they give rise to. Enhancements of solar wind density/dynamic pressure may also contribute to the auroral brightenings in these cases. This is the type of directly driven activity discussed by Newell and Sibeck (1993).

\section{Summary and conclusions}

In this paper we study a variety of PMAF activities in the context of the quasi-global dayside aurora and plasma convection cells consisting of the following basic elements: (i) PMAFs/prenoon in the $B_{y}$-distorted dawn-centered cell (see Fig. 17), (ii) the midday gap aurora with its brightening sequence (the MABS) located near the zero-point potential line (see Figs. 8 and 18), and (iii) PMAFs/postnoon in the $B_{y^{-}}$ distorted postnoon cell (see Fig. 10). Based on the observations reported in this paper and in recent work (Sandholt and Farrugia, 2007a,b) the status on the brightening history of PMAFs may be summarized as follows.

1. Type 1 PMAFs (absence of rebrightenings):

The type 1 events may be exemplified by the 09:0009:05 UT activity (PMAFs/postnoon/ $B_{y}>0$ ) on 4 December 1999 (Fig. 12).

2. Type 2 PMAFs (multiple brightening PMAFs): This study confirms the finding of Fasel (1995) that the majority of PMAFs are type 2 events. Clear type 2 brightening histories are observed in PMAFs/prenoon $/ B_{y}>0 \quad(12$ December 1999), PMAFs/postnoon $/ B_{y}>0 \quad(8$ December 1999), PMAFs/prenoon $/ B_{y}<0$ (8 January 1999,16 December 1998), and PMAFs/postnoon/ $B_{y}<0$ (8 January 1999, 30 November 1997). (The 30 November 1997, 16 December 1998, 8 December 1999 and 12 December 1999 cases are documented in Sandholt and Farrugia, 2007a). The different Birkeland current configurations in PMAFs/prenoon $/ B_{y}>0$ and PMAFs/postnoon $/ B_{y}>0$ may be reflected in a corresponding dawn-dusk asymmetry of the PMAF brightening histories as demonstrated in Sandholt and Farrugia (2007b).

3. Type 3 PMAFs ("same as PMAFs 2, but which slow down and stop while maintaining their luminosity for some time or rebrighten"):

Good examples of the long-lived type 3 events are the 07:35-07:50 UT (PMAFs/prenoon $/ B_{y}>0$ ) and the 09:15-09:25 UT (PMAFs/postnoon/ $B_{y}>0$ ) cases on 3 December 1997 (Fig. 3). The relative scarcity of types 1 and 3 events is illustrated by the fact that only few cases of these types were observed during our three selected days.

4. Sources of type 2 PMAFs:

(i) Occurrence under steady solar wind/IMF conditions may appear associated with transient flow shear at the boundary of a channel of enhanced convection of the type proposed by Southwood (Southwood, 1987) (see also Sandholt et al., 1990; Sandholt and Farrugia, 2007a). (ii) Type 2 rebrightenings do occur in association with IMF $B_{y}$ transients (see the abrupt increases of the negative $B_{y}$ component on 8 January 1999). In the 8 January 1999 case rebrightenings appear in the region of strong ionospheric flow shear (clockwise vorticity near zenith of optical cite; Figs. 19, 20 and 21) in the $B_{y^{-}}$ distorted convection cell in the postnoon sector. Thus they are FSAs.

(iii) Multiple X-line reconnection at the magnetopause, as suggested by Lee and Fu (1985), was discussed by Fasel et al. (1994b). Related to this we note the presence of multiple X-lines in recent MHD simulations of FTEs (Raeder, 2006; Omidi and Sibeck, 2007). 
5. Type 3 PMAFs and polar arcs adjacent to the cusp poleward boundary during IMF $B_{z}$ transients:

In the case of $B_{z}$ transients and $B_{y}>0$ polarity (see the 09:20 UT northward turnings on 3 December 1997 and 4 December 1999) the intense PBIs appear as intensified polar arcs expanding westward along the cusp poleward boundary, in the region of strong flow shear (clockwise flow vorticity) in strongly $B_{y}$-distorted convection cells. Thus, they are flow shear arcs (FSAs) directly driven by the IMF northward turnings. This ionospheric response is a temporal structure ("cusp in rapid transition" (Sandholt et al., 2002b; Escoubet et al., 2008)) caused by the altered reconnection configuration (see e.g. Moore et al., 2002) giving rise to expanding lobe cells appearing shortly after the IMF transitions (clock angle changes from $120-160^{\circ}$ to $\leq 90^{\circ}$ in our example). In this case the plasma convection configures as a composite pattern made up of a distorted 2-cell merging pattern and a lobe cell (Fig. 14). The 09:20 UT event on 3 December 1997 (clock angle approaching $90^{\circ}$ ) appears in the MSP data as a type 3 PMAF while the event on 4 December 1999 (clock angle approaching $45^{\circ}$ ) is not associated with PMAFs. Both are FSAs at the cusp poleward boundary related to transition states of the cusp configuration which may reflect an increased tilt of the reconnection line after the northward turning (see Moore et al., 2002). From the direct observations of the electron precipitation flux (reaching $5 \mathrm{keV}$ energy) on 4 December 1999 we infer that similar electron precipitation events, although mostly at lower energies, are present in the case of the type 3 PMAFs. Statistical observations from space indicate that such arcs show a maximum during the sunlit summer months (Frey et al., 2004). The present ground observations show that, given the appropriate interplanetary triggers, intense flow shear arcs are also present in winter.

Acknowledgements. We thank Bjørn Lybekk and Espen Trondsen for the preparation of the optical data. We thank the SuperDARN team for the plasma convection data. The optical observation program in Svalbard is supported by the Norwegian Research Council and the Norwegian Polar Research Institute. This work is supported in part by a NASA SEC-Guest Investigator grant, by grant NNG05GG25G as well as by NASA grant NNX08AD11G.

Topical Editor I. A. Daglis thanks P. T. Newell and N. Omidi for their help in evaluating this paper.

\section{References}

Carlson, H. C., Heelis, R. A., Weber, E. J., and Sharber, J. R.: Coherent mesoscale convection patterns during northward IMF, J. Geophys. Res., 93, 14 501-14 514, 1988.

Cogger, L. L., Murphree, J. J., Ismail, S., and Anger, C. D.: Characteristics of dayside $5577 \AA$ and $3914 \AA$ aurora, Geophys. Res. Lett., 4, 413-416, 1977.
Eriksson, S., Peria, W. J., Bonnell, J. W., Su, Y. J., Ergun, R. E., Tung, Y. K., Parks, G. K., and Carlson, C. W.: Lobe cell convection and polar cap precipitation, J. Geophys. Res., 108(A5), 1198, doi:10.1029/2002JA009725, 2003.

Eriksson, S., Baker, J. B. H., Petrinec, S. M., Wang, H., Rich, F. J., Kuznetsova, M., Dunlop, M. W., Reme, H., Greenwald, R. A., Frey, H. U., Luhr, H., Ergun, R. E., and Balogh, A.: On the generation of enhanced sunward convection and transpolar aurora in the high-latitude ionosphere by magnetic merging, J. Geophys. Res., 110, A11218, doi:10.1029/2005JA011149, 2005.

Escoubet, C. P., Berchem, J., Bosqued, J. M., Trattner, K. H. Taylor, M. G. G. T., Pitout, F., Laakso, H., Masson, A., Dunlop, M., Dandouras, I., Reme, H., Fazakerley, A. N., and Daly, P.: Effect of a northward turning of the IMF on cusp precipitation as observed by CLUSTER, J. Geophys. Res., 113, A07S13, doi:10.1029/2007JA012771, 2008.

Farrugia, C. J., Sandholt, P. E., Maynard, N. C., Torbert, R. B., and Ober, D. M.: Temporal variations in a four-sheet fieldaligned current system and associated aurorae as observed during a Polar-ground magnetic conjunction in the midmorning sector, J. Geophys. Res., 108(A6), 1230, doi:10.1029/2002JA009619, 2003.

Fasel, G.: Dayside poleward moving auroral forms: A statistical study, J. Geophys. Res., 100, 11 891-11 906, 1995.

Fasel, G. J., Minow, J. I., Lee, L. C., Smith, R. W., and Deehr, C. S.: Poleward-moving auroral forms: What do we really know about them?, in: Physical Signatures of Magnetospheric Boundary Layer Processes, edited by: Holtet, J. A. and Egeland, A., vol. 425 of NATO ASI Series, pp. 211-226, Kluwer Academic Publishers, Dordrecht, Holland, 1994a.

Fasel, G. J., Minow, J. I., Smith, R. W., Deehr, C. S., and Lee, L. C.: Multiple brightenings of poleward-moving auroral forms, in: Solar Wind Sources of Magnetospheric Ultra-Low-Frequency Waves, edited by: Engebretson, M. J., Takahashi, K., and Scholer, M., vol. 81, p. 201, AGU, Washington, D.C., 1994b.

Frey, H., Immel, T. J., Lu, G., Bonnel, J., Fuselier, S. A., Mende, S. B., Hubert, B., Østgaard, N., and Le, G.: Properties of localized, high-latitude, dayside aurora, J. Geophys. Res., 108(A4), 8008, doi:10.1029/2002JA009332, 2003.

Frey, H. U., Østgaard, N., Immel, T. J., Korth, A., and Mende, S.: Seasonal dependence of localized, high-latitude dayside aurora (HiLDA), J. Geophys. Res., 109, A04303, doi:10.1029/2003JA010293, 2004.

Goertz, C. K., Nielsen, E., Korth, A., Glassmeier, K. H., Haldoupis, C., Hoeg, P., and Hayward, D.: Observations of a possible ground signature of flux transfer events, J. Geophys. Res., 90, 4069-4078, 1985.

Greenwald, R. A., Baker, K., Dudeney, J. R., Pinnock, M., Thomas, E. C., Villain, J. P., Cerisier, J.-C., Senior, C., Hanuise, C., Hunsucker, R. D., Sofko, G. J., Koehler, J., Nielsen, E., Pellinen, R., Walker, A. D. M., Sato, N., and Yamagishi, H.: DARN/SUPERDARN: A Global View of the Dynamics of HighLatitude Convection, Space Sci. Rev., 71, 761-796, 1995.

Iijima, T. and Potemra, T.: Large scale characteristics of fieldaligned currents associated with substorms, J. Geophys. Res., 83, 599-615, 1978.

Kan, J. R., Deehr, C. S., Lyu, L. H., and Newell, P. T.: Ionospheric signatures of the patchy and intermittent reconnection at the dayside magnetopause, J. Geophys. Res., 101, 10 939-10 945, 1996. 
Karlson, K. A., Øieroset, M., Moen, J., and Sandholt, P. E.: A statistical study of flux transfer event signatures in the dayside aurora: The IMF $B_{y}$-related prenoon-postnoon asymmetry, J. Geophys. Res., 101, 59-68, 1996.

Lee, L. C. and Fu, Z. F.: A theory of flux transfer at the magnetopause, Geophys. Res. Lett., 12, 105-108, 1985.

Lepping, R. P., Acũna, M. H., Burlaga, L. F., Farrell, W. M., Slavin, J. A., Schatten, K. H., Mariani, F., Ness, N. F., Neubauer, F. M., Whang, Y. C., Byrnes, J. B., Kennon, R. S., Panetta, P. V., Scheifele, J., and Worley, E. M.: The WIND magnetic field investigation, Space Sci. Rev., 71, 207-229, 1995.

Maynard, N. C., Burke, W. J., Sandholt, P. E., Moen, J., Ober, D. M., Lester, M., Weimer, D. R., and Egeland, A.: Observations of simultaneous effects of merging in both hemispheres, J. Geophys. Res., 106, 24 551-24 578, 2001.

McHenry, M. A. and Clauer, C. R.: Modeled ground magnetic signatures of flux transfer events, J. Geophys. Res., 92, 11231$11240,1987$.

Moore, T. E., Fok, M.-C., and Chandler, M. O.: The dayside reconnection X line, J. Geophys. Res., 107(A10), 1332, doi:10.1029/2002JA009381, 2002.

Newell, P. T. and Sibeck, D. G.: $B_{y}$ fluctuations in the magnetosheath and azimuthal flow velocity transients in the dayside ionosphere, Geophys. Res. Lett., 20, 1719-1722, 1993.

Newell, P. T., Wing, S., and Meng, C.-I.: Spectral properties and source regions of dayside electron acceleration events, J. Geophys. Res., 110, A11205, doi:10.1029/2005JA011264, 2005.

Ogilvie, K. W., Chornay, D., Fritzenreiter, R., Hunsaker, F., Keller, J., Lobell, J., Miller, G., Scudder, J. D., Sittler Jr., E. C., Torbert, R. B., Bodet, D., Needell, G., Lazarus, A. J., Steinberg, J., T., Tappan, J. H., Mavretic, A., and Gergin, E.: SWE, a comprehensive plasma instrument for the WIND spacecraft, Space Sci. Rev., 71, 55-99, 1995.

Oksavik, K., Moen, J., and Carlson, H. C.: High-resolution observations of the small-scale flow pattern associated with a poleward moving auroral form in the cusp, Geophys. Res. Lett., 31, L11807, doi:10.1029/2004GL019838, 2004.

Oksavik, K., Moen, J., Carlson, H. C., Greenwald, R. A., Milan, S. E., Lester, M., Denig, W. F., and Barnes, R. J.: Multiinstrument mapping of small-scale flow dynamics related to a cusp auroral transient, Ann. Geophys., 23, 2657-2670, 2005, http://www.ann-geophys.net/23/2657/2005/.

Omidi, N. and Sibeck, D. G.: Flux transfer events in the cusp, Geophys. Res. Lett., 34, L04106, doi:10.1029/2006GL028698, 2007.

Raeder, J.: Flux Transfer Events: 1. generation mechanism for strong southward IMF, Ann. Geophys., 24, 381-392, 2006, http://www.ann-geophys.net/24/381/2006/.

Reiff, P. H., Burch, J. L., and Heelis, R. A.: Dayside auroral arcs and convection, Geophys. Res. Lett., 5, 391-394, 1978.

Ruohoniemi, J. M. and Baker, K. B.: Large-scale imaging of highlatitude convection with Super Dual Auroral Radar Network HF radar observations, J. Geophys. Res., 103, 20 797-20 811, 1998.

Russell, C. T. and Elphic, R. C.: Initial ISEE magnetometer results: Magnetopause observations, Space Sci. Rev., 22, 681-715, 1978.

Sandholt, P. E. and Farrugia, C. J.: Does the aurora provide evidence for the occurrence of antiparallel magnetopause reconnection?, J. Geophys. Res., 108(A12), 1466, doi:10.1029/2003JA010066, 2003.

Sandholt, P. E. and Farrugia, C. J.: Spatiotemporal structure of the reconnecting magnetosphere under $B_{y}$-dominated interplanetary magnetic cloud conditions, J. Geophys. Res., 111, A10209, doi:10.1029/2005JA011514, 2006.

Sandholt, P. E. and Farrugia, C. J.: Poleward moving auroral forms (PMAFs) revisited: responses of aurorae, plasma convection and Birkeland currents in the pre- and postnoon sectors under positive and negative IMF $b_{y}$ conditions, Ann. Geophys., 25, 16291652, 2007a,

http://www.ann-geophys.net/25/1629/2007/.

Sandholt, P. E. and Farrugia, C. J.: The role of poleward moving auroral forms in the dawn-dusk precipitation asymmetries induced by IMF $B_{y}$, J. Geophys. Res., 112, A04203, doi:10.1029/2006JA011952, 2007b.

Sandholt, P. E. and Newell, P. T.: Ground and satellite observations of an auroral event at the cusp/cleft equatorward boundary, J. Geophys. Res., 97, 8685-8691, 1992.

Sandholt, P. E., Deehr, C. S., Egeland, A., Lybekk, B., Viereck, R., and Romick, G. J.: Signatures in the dayside aurora of plasma transfer from the magnetosheath, J. Geophys. Res., 91, 10063 $10079,1986$.

Sandholt, P. E., Lockwood, M., Oguti, T., Cowley, S. W. H., Freeman, K. S. C., Lybekk, B., Egeland, A., and Willis, D. M.: Midday auroral breakup events and related energy and momentum transfer from the magnetosheath, J. Geophys. Res., 95, 10391060, 1990.

Sandholt, P. E., Moen, J., Rudland, A., Opsvik, D., Denig, W. F., and Hansen, T.: Auroral event sequences at the dayside polar cap boundary for positive and negative interplanetary magnetic field $B_{y}$, J. Geophys. Res., 98, 7737-7755, 1993.

Sandholt, P. E., Denig, W. F., Farrugia, C. J., Lybekk, B., and Trondsen, E.: Auroral structure at the cusp equatorward boundary: Relationship with the electron edge of low-latitude boundary layer precipitation, J. Geophys. Res., 107(A9), 1235, doi:10.1029/2001JA005081, 2002a.

Sandholt, P. E., Farrugia, C. J., Moen, J., and Denig, W. F.: The cusp in rapid transition, J. Geophys. Res., 107(A12), 1427, doi:10.1029/2001JA009214, 2002b.

Sandholt, P. E., Farrugia, C. J., and Denig, W. F.: Dayside aurora and the role of IMF $\left|B_{y} / B_{z}\right|$ : detailed morphology and response to magnetopause reconnection, Ann. Geophys., 22, 613628,2004 ,

http://www.ann-geophys.net/22/613/2004/.

Sandholt, P. E., Dyrland, M., and Farrugia, C. J.: Dayside aurorae and polar arcs under south-east IMF orientation, Ann. Geophys., 24, 3421-3432, 2006, http://www.ann-geophys.net/24/3421/2006/.

Southwood, D. J.: The ionospheric signature of flux transfer events, J. Geophys. Res., 92, 3207-3213, 1987.

Taguchi, S., Sugiura, M., Winningham, J. D., and Slavin, J.: Characterization of the IMF $B_{y}$-dependent field-aligned currents in the cleft region based on DE 2 observations, J. Geophys. Res., 98, 1393-1407, 1993.

Vorobjev, V. G., Gustafsson, G., Starkov, G. V., Feldstein, Y. I., and Shevnina, N. F.: Dynamics of day and night aurora during substorms, Planet. Space Sci., 23, 269-278, 1975.

Weimer, D. R.: Models of high-latitude electric potentials derived with a least error fit of spherical harmonic coefficients, J. Geophys. Res., 100, 19595-19608, 1995. 